\title{
Bulanık TOPSIS ve Bulanık VIKOR Yöntemleriyle Alışveriş Merkezi Kuruluş Yeri Seçimi ve Bir Uygulama
}

\author{
Selection of Shopping Center Location with The Methods of Fuzzy VIKOR and Fuzzy \\ TOPSIS and An Application
}

Selahattin YAVUZ1 ${ }^{1}$, Muhammet DEVECi²

\begin{abstract}
ÖZET
İşletmelerin artan rekabet koşulları nedeniyle pazarda faaliyetlerini sürdürebilmesi için yer seçimiyle ilgili doğru kararlar vermesi çok önemlidir. Yanlış yer seçimi işletmeler için büyük zararlara, hatta iflasa sebep olabilmektedir. Kendileri için yer seçiminin çok önemli olduğu sektörlerin başında Alışveriş Merkezleri (AVM) gelmektedir. Alışveriş Merkezi (AVM) olarak seçilecek yer; müşteri potansiyelinin yüksek olduğu, düşük maliyet ve yüksek kârı sağlayabilecek bir yer olmalıdır. Bu çalışmada, Erzincan ilinde yeni bir AVM açılmasına karar verilmesi durumunda, olası kuruluş yerinin belirlenmesine çalışılmıştır. Bunun için birden fazla karar vericiyle, birçok alternatif arasından doğru olan alternatifi seçmek için Çok Kriterli Karar Verme (ÇKKV) tekniklerinden yararlanılıış̧ı. Çalışmada, Çok Kriterli Karar Verme (ÇKKV) tekniklerinden Bulanık TOPSIS ve Bulanık ViKOR teknikleriyle, Erzincan için AVM kuruluş yeri seçimi için potansiyel bölgelerin değerlendirilmesi ve bunun sonucunda en uygun yer seçimi belirlenmeye çalışılmıştır.
\end{abstract}

Anahtar Kelimeler: Kuruluş yeri seçimi, çok kriterli karar verme, bulanık mantık

\section{GiRiş}

Kuruluş yeri seçimi gibi stratejik kararların çoğu, birbirleriyle çelişen pek çok kriterin dikkate alınması gerektiren kararlardır. Bu yüzden, bu tip kararlarda tüm değerlendirme kriterelerini değerlendirme sürecine dahil edecek yöntemlerin kullanılması gerekmektedir. Bu eksikliğin giderilmesi amacıyla bu tip problemlerin çözümü için Çok Kriterli Karar Verme (ÇKKV) yöntemleri geliştirilmiştir. ÇKKV, birden fazla kritere göre bir karar kümesi içinden ve karar vericinin karar verme durumuna bağlı olarak en iyi kararı seçme işlemidir (Alpay, 2010). Literatür tarandığında, ÇKKV yöntemlerinin bulanık küme teorisi ile birlikte kullanılması sonucunda oluşan bulanık ÇKKV yöntemleri, son yıllarda sıklıkla tercih edilen karar verme yöntemleri olduğu görülmektedir (Demir, 2010). Alışveriş Merkezi (AVM) kuruluş yeri seçimi probleminin çözümünde kullanılan yöntemlerden ilki olan Bulanık TOPSIS; pozitif ideal çözümden en kısa, negatif ideal

\begin{abstract}
Due to the increasing competition in the market, taking right decisions about the location selection for businesses is very important. The wrong choice of location for businesses may cause to large losses even bankruptcy. Shopping Centers (AVM) sector is the first sector for which the location selection is quite important. A location chosen as Shopping Center (AVM) should be a place providing high customer potential, low cost and high profit. In this study, the case of a business making a decision to open a new AVM in the province of Erzincan is studied to determine the possible location of a new shopping center. For this purpose we studied with more than one decision makers and Multi-Criteria Decision Making (MCDM) techniques were used to choose the right alternative among the wide range of alternatives. In this study by using techniques of Fuzzy TOPSIS and Fuzzy VIKOR, belonging to Multiple Criteria Decision Making (MCDM) techniques, it is examined to determine the evaluation and selection of the most appropriate potential location for the shopping center in province of Erzincan.
\end{abstract}

Keywords: Facility location selection, multiple criteria making decision, fuzzy logic

çözümden en uzak mesafedeki alternatifin seçilmesi olarak ifade edilmektedir. İkinci yöntem olan Bulanık ViKOR yöntemi ise, uzlaşmacı sıralama listesini ve çözümü belirtir (Opricovic ve Tzeng, 2004). Bu yöntemler, Çok Kriterli Karar Verme tekniklerinden sadece iki tanesidir. Opricovic ve Tzeng (2004), çalışmalarında her iki yöntemin temel farklılıklarını normalizasyon, toplama ve çözüm teknikleri bakımından açıklamaya çalışmışlardır. Bulanık ViKOR ve TOPSIS yöntemlerinde alternatiflerin sıralaması yapılırken $Q$ ve yakınlık katsayısı $\left(C_{i}\right)$ indeksinin değerlerine bakılır. ViKOR yönteminde $Q_{i}$ indeksinin " 0 " değerine yakın olması, TOPSis yönteminde ise $C_{1}^{\prime}$ 'nin "1" değerine yakın olması istenir. ÇKKV yöntemlerinin çözümü için ilk kez, 1981 yılında ortaya atılan TOPSIS yöntemi Hwang ve Yoon (1981); pozitif ideal çözüme en yakın ve negatif ideal çözüme en uzak alternatifleri belirleme ve buna göre alternatifler arasında bir sıralama yapma prensibine dayanmaktadır (Chen, 2000). 
Bu çalışmada Erzincan ili için, Bulanık TOPSIS ve Bulanık ViKOR yöntemleriyle çözüm aranan AVM kuruluş yeri seçim problemi kapsamında; şehir merkezine uzaklıklarına göre belirlenen 5 alternatif bölge, karar vericilerle yapılan görüşmeler ve ilgili literatür araştırması sonucunda 14 kriter (yetenekli işgücü, yatırım maliyeti, toplum tutumu, trafik, sosyal ve kültürel çevre, altyapı uygunluğu, müşterilere yakınlık, genişleyebilirlik, potansiyel talep, arazi özellikleri, yasal sınırlamalar ve teşvikler, tedarikçilere ve kaynaklara yakınlık, enerji ve yakıt bulunabilirliği, iklim koşulları) dikkate alınarak değerlendirmeye tabi tutulmuş ve nihayetinde her iki yöntemin ortaya koymuş olduğu bulgular, karşılaştırmalı olarak analiz edilmiştir.

\section{KURULUŞ YERI SEÇiMi}

Bu bölüm, kuruluş yeri seçim kriterlerini, problemin genel yapısını ve bu problemin çözümünde kullanılan yöntemleri belirlemeye yönelik literatür araştırmasını göstermektedir. Karar verici konumundaki yöneticilerin, kuruluş yeri seçim planlamasını matematiksel veya analitik yöntemlerle gerçekleştirmeleri, problemin başında belirledikleri hedeflere daha hızlı ulaşmalarını sağlayacaktır. Bu noktada karar vericiler, yatırım maliyetlerinin düşük ve kârın yüksek olması başta olmak üzere çok sayıda kriteri göz önüne alıp, birçok alternatifi değerlendirmek durumundadırlar. Aynı anda birçok ölçütün optimize edilmesi ise karar sürecini oldukça karmaşıklaştırmaktadır. Bu durumda ÇKKV uygulanarak bu sorun giderilebilmektedir (Aydın, 2009).

Kuruluş yeri seçim problemlerinde, çok kriterli karar verme teknikleri ile bulanık mantığı kullanan birçok yazar bulunmaktadır. Bu yazarlar Çınar (2010), Liang ve Mao-jiun (1991), Chou vd. (2008), Chou (2010), Kahraman vd. (2003), Kaya ve Çınar (2007), Chu (2002), Hu vd. (2009), Ertuğrul ve Karakaşoğlu (2008), Kaboli vd. (2007), Demirel vd. (2010), Özdağoğlu (2011), Doğan (2012) tarafından kullanılmıştır. Örneğin Demirel vd. (2010) yılında yaptıkları çalışmada Choquet integrali ile bir depo yeri seçimi yapmıştır. Chu 2002 yılında bulanık TOPSIS yaklaşımıyla kuruluş yeri seçimi yapmıştır. Hu vd. (2009) yılında yaptıkları çalışmada dağıtım merkezi yerleşim seçimi için bulanıkTOPSIS yaklaşımını kullanmışlardır.

Tablo 1: AVM Kuruluş Yeri Seçiminde Kullanılan Kriterler

\begin{tabular}{|l|l|}
\hline \multicolumn{1}{|c|}{ Kriterler } & \multicolumn{1}{c|}{ Kaynaklar } \\
\hline $\begin{array}{l}C_{1}: \text { Insan Kaynağı } \\
\text { (Yetenekli İ̧̧ücü Tedariki) }\end{array}$ & $\begin{array}{l}\text { Liang ve Mao-jiun (1991), Russell ve Taylor (1999), Chu (2002), Kahraman vd. (2003), } \\
\text { Demirel vd. (2010), Ersoy (2011), Kobu (2008), Momeni vd. (2011), Tavakkoli-Moghaddam } \\
\text { vd. (2011), Doğan (2012) }\end{array}$ \\
\hline$C_{2}:$ Yatırım Maliyeti & $\begin{array}{l}\text { Liang ve Mao-jiun (1991), Chu (2002), Kaya ve Çınar (2007), Momeni vd. (2011), Tavakkoli- } \\
\text { Moghaddam vd. (2011) }\end{array}$ \\
\hline$C_{3}:$ Toplum Tutumu & Chu (2002), Doğan (2012), Ertuğrul ve Karakaşoğlu (2008) \\
\hline$C_{4}:$ Trafik & Deluka-Tibljas (2011), Özdağoğlu (2011) \\
\hline$C_{5}:$ Sosyal ve Kültürel Çevre & Deluka-Tibljas (2011), Kaya ve Çınar (2007), Demirel vd. (2010), Özdağoğlu (2011) \\
\hline$C_{6}:$ Altyapı Uygunluğu & Kahraman vd. (2003), Demirel vd. (2010), Özdağoğlu (2011) \\
\hline$C_{7}:$ Müşterilere Yakınlık & $\begin{array}{l}\text { Michael vd. (1998), Kahraman vd. (2003), Ertuğrul ve Karakaşoğlu (2008), Kaya ve Çınar } \\
\text { (2007) }\end{array}$ \\
\hline$C_{8}:$ Genişleyebilirlik & Momeni vd. (2011), Tavakkoli-Moghaddam vd. (2011) \\
\hline$C_{9}:$ Potansiyel Talep & Özdağoğlu (2011) \\
\hline$C_{10}:$ Arazi Özellikleri & Kobu (2008) \\
\hline$C_{11}:$ Yasal Sınırlamalar ve Teşvikler & Russell ve Taylor (1999), Ersoy (2011), Aytekin vd. (2005) \\
\hline $\begin{array}{l}C_{12}: \text { Tedarikçilere \& Kaynaklara } \\
\text { yakınlık }\end{array}$ & $\begin{array}{l}\text { Ertuğrul ve Karakaşoğlu (2008), Kaya ve Çınar (2007), Momeni vd. (2011), Özdağoğlu } \\
\text { (2011), Tavakkoli-Moghaddam vd. (2011) }\end{array}$ \\
\hline$C_{13}:$ Enerji ve Yakıt Bulunabilirliği & Russell ve Taylor (1999), Kobu (2008) \\
\hline$C_{14}:$ :klim Koşulları & Russell ve Taylor (1999) \\
\hline
\end{tabular}

(Kaynak: Deveci ve Kuvvetli, 2012)

\section{BULANIK KÜME TEORISI}

Bulanık küme teorisi 1965 yılında Lütfü Askerzade (Lotfi Askar Zadeh) tarafından geliştirilmiştir (Zadeh, 1965). Klasik mantıkta evet-hayır, doğru-yanlış, siyahbeyaz, uzun-kısa, yavaş-hızlı gibi kavramların kesin sınırları vardır. Bulanık mantıkta ise, kavramların kesin sınırlamaları olmaksızın sınıflandırılabilir. Örneğin, çok sıcak, çok düşük, yüksek maaş ve orta boy gibi kişiden kişiye değişen ifadeler kullanılır. Bir bulanık kümede elemanın üyelik derecesi 1'e ne kadar yakın ise elemanın o kümeye üyeliğinin o derece yüksek olduğunu, üyelik derecesinin sıfır olması ise bulanık kümenin 
dışında olduğu anlaşılmaktadır. Klasik mantıkta elemanın üyelik değeri $\{0,1\}$ gibi iki değerle sınırlı iken, bulanık küme kuramında bu değer $[0,1]$ aralığında herhangi bir sayı olabilmektedir.

Günümüzde birçok alanda uygulanan bulanık mantık, belirsizlik içeren problemler ve yargıları çözmede kullanılmaktadır. Bu belirsizlikleri sayısal de- ğerler ile ifade etmek mümkün olamayabilir. Sayısal değerler yerine dilsel değişkenler kullanılabilir. Bu çalışmada kuruluş yeri seçimi için kullanılan üyelik fonksiyonu, üçgen bulanık sayılardır. Üçgen üyelik fonksiyonu I, m ve u olmak üzere üç parametre ile tanımlanır. Burada I ve u sırasıyla bulanık sayısının alt ve üst sınır değerlerini, $m$ ise orta değerini ifade eder (Salehi ve Tavakkoli-Moghaddam, 2008).

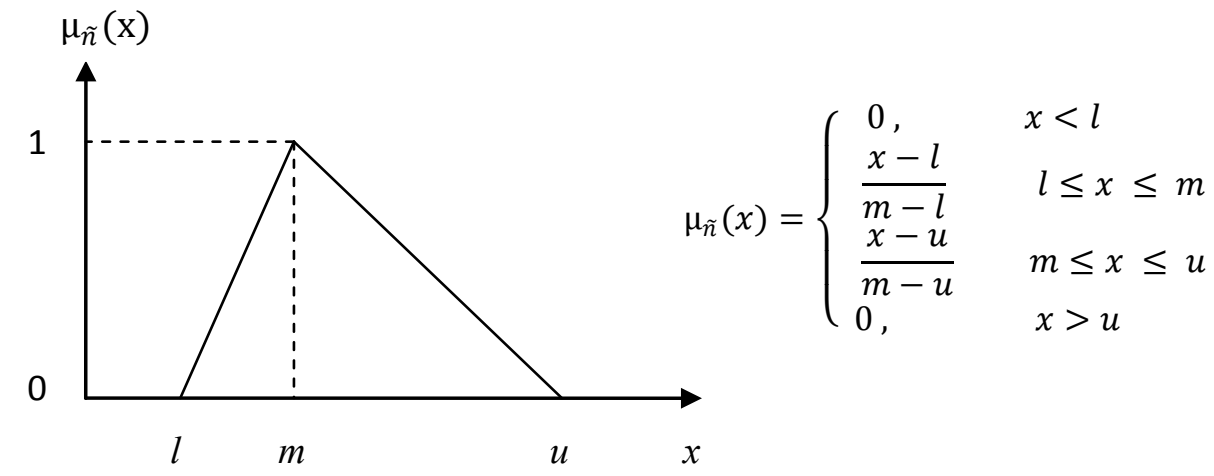

Şekil 1: Üçgensel Üyelik Fonksiyonu

(Kaynak: Chen, 2000)

\section{BULANIK VIKOR YÖNTEMi}

Vikor yöntemi, Opricovic (1998) tarafından çok ölçütlü kompleks sistemlerin optimizasyonu için geliştirilen Çok Kriterli Karar Verme (ÇKKV) yöntemlerden biridir. Yöntemin amacı, alternatiflerin sıralanması ve seçim aşamasında, maksimum grup faydası (çoğunluk kuralı) ve minimum bireysel pişmanlığı sağlayacak, uzlaştırıcı çözüme ulaşmaktır. Yöntem, alternatifler arasından yapılan seçim sürecinde nihai karar üzerinde birden fazla kriterin dikkate alınması zorunluluğunun olduğu haller için önerilmektedir (Opricovic ve Tzeng, 2004). Bulanık küme teorisinin ViKOR yöntemine uygulanma sonucu oluşan bulanık ViKOR yöntemi, bulanık çevrede nihai karar üzerinde belirleyici olan ve birbirleriyle çatışan farklı kriterlerin söz konusu olduğu durumlarda kullanılması uygun olan bir yöntemdir. Söz konusu bu yöntem; bulanık bir ortamda, kriter ve ağırlıklarının her ikisini de bulanıklaştırmaktadır (Opricovic, 2011). Aşağıda kullanılan formüller Opricovic ve Teng (2004) tarafından yayınlanan eserden yararlanılmıştır. Çok kriterli karar problemlerinin bulanık ViKOR yönetimi kullanılarak çözümünde aşağıda adımlar takip edilmektedir:

Adım 1: " $\mathrm{n}$ " sayıda uzman kişiden oluşan bir karar verici grubu oluşturulur.

Adım 2: " $k$ " adet değerlendirme kriteri ve " $\mathrm{m}$ " adet alternatif belirlenir.

Adım 3: Kriterlerin ve alternatiflerin değerlendirilmesi için uygun dilsel değişkenler belirlenir. Kriter ağırlıklarının ve alternatiflerin önem derecelerinin belirlenmesi için kullanılan dilsel değişkenler ve bunlara karşılık gelen bulanık sayılar Tablo 2'de gösterilmiştir.

Tablo 2: Dilsel Değişkenler ve Bulanık Sayı Değerleri

\begin{tabular}{|c|c|c|c|}
\hline \multicolumn{2}{|c|}{$\begin{array}{c}\text { Kriter Ağırlıkları için Dilsel } \\
\text { Değişkenler }\end{array}$} & \multicolumn{2}{|c|}{$\begin{array}{c}\text { Alternatiflerin } \\
\text { Derecelendirilmesi için Dilsel } \\
\text { Değişkenler }\end{array}$} \\
\hline $\begin{array}{l}\text { Dilsel } \\
\text { Değişkenler }\end{array}$ & $\begin{array}{l}\text { Bulanık } \\
\text { Sayılar }\end{array}$ & $\begin{array}{c}\text { Dilsel } \\
\text { Değişkenler }\end{array}$ & Bulanık Sayılar \\
\hline Çok Düşük (ÇD) & $\begin{array}{c}(0.00,0.00 \\
0.10)\end{array}$ & $\begin{array}{l}\text { Çok Kötü } \\
\text { (ÇK) }\end{array}$ & $\begin{array}{c}(0.00,0.00 \\
1.00)\end{array}$ \\
\hline Düşük (D) & $\begin{array}{c}(0.00,0.10 \\
0.30)\end{array}$ & Kötü (K) & $\begin{array}{l}(0.00,1.00 \\
3.00)\end{array}$ \\
\hline Orta Düşük (OD) & $\begin{array}{c}(0.10,0.30 \\
0.50)\end{array}$ & $\begin{array}{l}\text { Orta Kötü } \\
\text { (OK) }\end{array}$ & $\begin{array}{c}(1.00,3.00 \\
5.00)\end{array}$ \\
\hline Orta (O) & $\begin{array}{c}(0.30,0.50 \\
0.70)\end{array}$ & Orta (O) & $\begin{array}{l}(3.00,5.00 \\
7.00)\end{array}$ \\
\hline Orta Yüksek (OY) & $\begin{array}{c}(0.50,0.70 \\
0.90)\end{array}$ & Orta İyi (Oi) & $\begin{array}{l}(5.00,7.00 \\
9.00)\end{array}$ \\
\hline Yüksek (Y) & $\begin{array}{c}(0.70,0.90 \\
1.00)\end{array}$ & İyi (i) & $\begin{array}{c}(7.00,9.00 \\
10.00)\end{array}$ \\
\hline Çok Yüksek (Y) & $\begin{array}{c}(0.90,1.00, \\
1.00)\end{array}$ & Çok İyi (Çi) & $\begin{array}{c}(9.00,10.00 \\
10.00)\end{array}$ \\
\hline
\end{tabular}

(Kaynak: Chen, 2000)

Adım 4: Her bir kriterin ve alternatifin bulanık ağırlıkları (1) ve (2) numaralı eşitlikler yardımıyla hesaplanır. Eşitliklerdeki " $n$ " gruptaki karar verici sayısını ifade etmektedir. 
$\tilde{w}_{\mathrm{j}}=\frac{1}{\mathrm{n}}\left[\sum_{\mathrm{y}=1}^{\mathrm{n}} \tilde{\mathrm{w}}_{\mathrm{j}}^{\mathrm{y}}\right], \quad \mathrm{j}=1,2, \ldots, \mathrm{k}$

$\tilde{x}_{\mathrm{ij}}=\frac{1}{\mathrm{n}}\left[\sum_{\mathrm{y}=1}^{\mathrm{n}} \tilde{\mathrm{x}}_{\mathrm{ij}}^{\mathrm{y}}\right], \quad \mathrm{i}=1,2, \ldots, \mathrm{m}$

$\tilde{x}_{\mathrm{ij}}$, "j" kritere göre; "i" alternatifinin derecesi ve $\tilde{w}_{\mathrm{j}}$ ise; "j" kriterinin önem ağırlığıdır.

Adım 5: (3) ve (4) numaralı eşitlikler yardımıyla bulanık karar matrisi oluşturulur.

$$
\begin{aligned}
& \tilde{D}=\left[\begin{array}{cccc}
\mathrm{x}_{11} & \mathrm{x}_{12} & \ldots & \mathrm{x}_{1 \mathrm{j}} \\
\mathrm{x}_{21} & \mathrm{x}_{22} & \ldots & \mathrm{x}_{2 \mathrm{j}} \\
\vdots & \vdots & \ldots & \vdots \\
\tilde{\mathrm{x}_{11}} & \mathrm{x}_{\mathrm{i} 2} & \ldots & \mathrm{x}_{\mathrm{ij}}
\end{array}\right], \quad \mathrm{i}=1,2, \ldots, \mathrm{m} ; \mathrm{j}=1,2, \ldots, \mathrm{k} \\
& \tilde{w}=\left[\tilde{w}_{1}, \tilde{w}_{2}, \ldots \ldots, \tilde{w}_{\mathrm{n}}\right] \text {, }
\end{aligned}
$$

Burada $\tilde{x}_{\mathrm{ij}}$, j. kritere göre i. alternatifin derecesi ve $\tilde{w}_{\mathrm{n}}$ ise $\mathrm{n}$.kriterin önem ağırlığıdır.

$\tilde{D}$ ise bulanık karar matrisini ifade etmektedir.

Adım 6: Tüm kriter fonksiyonlarının, bulanık en iyi ve en kötü değerleri belirlenir (i=1,2,..n). (5) numaralı eşitlik en iyi, (6) numaralı eşitlik ise en kötü değerlerin hesaplanması için kullanılmaktadır.

$$
\begin{gathered}
\tilde{f}_{i}^{*}=\max _{\mathrm{ij}}, \\
\tilde{f}_{i}^{-}=\max _{\mathrm{ij}}, \\
\mathrm{j}
\end{gathered}
$$

Adım 7: $\tilde{\mathrm{S}}_{\mathrm{j}}(7)$ ve $\tilde{\mathrm{R}}_{\mathrm{j}}(8)$ değerleri, $\mathrm{j}=1,2, \ldots, \mathrm{n}$ için hesaplanır

$$
\begin{gathered}
\widetilde{\mathrm{S}}_{\mathrm{j}}=\sum_{\mathrm{j}=1}\left[\tilde{w}_{\mathrm{i}}\left(\tilde{f}_{\mathrm{i}}^{*}-\mathrm{x}_{\mathrm{ij}}\right) /\left(\tilde{f}_{\mathrm{i}}^{*}-\tilde{f}_{\mathrm{i}}^{-}\right)\right], \\
\tilde{R}_{\mathrm{j}}=\max \left[\tilde{w}_{\mathrm{i}}\left(\tilde{f}_{\mathrm{i}}^{*}-\mathrm{x}_{\mathrm{ij}}\right) /\left(\tilde{f}_{\mathrm{i}}^{*}-\tilde{f}_{\mathrm{i}}^{-}\right)\right],
\end{gathered}
$$$$
\text { i }
$$

Burada $\tilde{\mathcal{W}}_{\mathrm{i}}$ kriterlerin ağırlığını ve önemini ifade ederken, $\tilde{\mathrm{S}}_{\mathrm{j}}$, "i" alternatifinin bütün kriterlere en iyi bulanık değerlere uzaklığının toplamını, $\tilde{R}_{\mathrm{j}}$ değeri ise "j." kritere göre "i" alternatifinin, bulanık en kötü değerlere maksimum uzaklığıdır (Akyüz, 2012).

Adım 8: Maksimum grup faydasını ifade eden $\tilde{\mathrm{S}}_{\mathrm{j}}$ , $\tilde{\mathrm{S}}_{j}^{*}$ (9), $\tilde{R}_{\mathrm{j}}, \tilde{R}^{*}(10)$ ve $\tilde{Q}_{\mathrm{i}}(11)$ değerleri hesaplanır.

$$
\begin{gathered}
\widetilde{\mathrm{S}}^{*}=\min _{\mathrm{i}} \widetilde{\mathrm{S}}_{\mathrm{i}}, \quad \widetilde{\mathrm{S}}^{-}=\max _{\mathrm{i}} \widetilde{\mathrm{S}}_{\mathrm{i}} \\
\widetilde{\mathrm{R}}^{*}=\min _{\mathrm{i}} \widetilde{\mathrm{R}}_{\mathrm{i}}, \quad \widetilde{\mathrm{R}}^{-}=\max _{\mathrm{i}} \widetilde{\mathrm{R}}_{\mathrm{i}}
\end{gathered}
$$

$$
\tilde{Q}_{\mathrm{i}}=\mathrm{v}\left(\tilde{S}_{\mathrm{i}}-\tilde{S}^{*}\right) /\left(\tilde{S}^{-}-\tilde{S}^{*}\right)+(1-\mathrm{v})\left(\tilde{R}_{\mathrm{i}}-\tilde{R}^{*}\right) /\left(\tilde{R}^{-}-\tilde{R}^{*}\right)
$$

$\tilde{S}^{*}$, uzlaştırıcı çoğunluk kuralını ve $\tilde{R}^{*}$ ise farklı görüştekilerin minimum bireysel pişmanlığını ifade etmektedir. Bu hesaplamalardan sonra $\tilde{Q}_{\mathrm{i}}$ indeksi elde edilir; bu indeks grup faydası ile bireysel pişmanlığın birlikte değerlendirilmesi ile hesaplanır. "v" değeri ise, kriterlerin çoğunluğunu veya maksimum gr up faydasını $(v=0.5)$ sağlayan stratejinin önemine dikkat çekerken, "1-v" bireysel pişmanlık değerine karşılık gelmektedir (Opricovic, 2011).

Adım 9: Üçgensel bulanık sayılar durulaştırılır ve alternatifler " $\tilde{Q}_{\mathrm{i}}$ " indeksine göre sıralanır. Bu indeksin, en küçük değeri en iyi alternatifi gösterir. Bu çalışmada, Hsieh vd. (2004) tarafından önerilen (12) eşitliğinde verilen BNP (Best Nonfuzzy Performance Value) durulaştırma yöntemi kullanılmıştır.

$$
\operatorname{BNP}_{\mathrm{i}}=\frac{\left(\mathrm{u}_{\mathrm{i}}-\mathrm{l}_{\mathrm{i}}\right)+\left(\mathrm{m}_{\mathrm{i}}-\mathrm{l}_{\mathrm{i}}\right)}{3}+1_{\mathrm{i}}
$$

Adım 10: Uzlaştırıcı çözümü belirlemek için aşağıdaki iki koşulun uygunluğu kontrol edilir.

1.Koşul: Kabul edilebilir avantaj

$Q\left(a^{\prime \prime}\right)-Q\left(a^{\prime}\right) \geq D Q$

$\mathrm{DQ}=\frac{1}{\mathrm{~m}-1}$ (eğer $\mathrm{m} \leq 5$ ise $\left.D Q=0.25\right) ; \mathrm{m}$ alternatif sayısını ifade eder )

2.Koşul: Karar vermede kabul edilebilir istikrar

Alternatif a', S ve/veya R değerlerine göre yapılan sıralamada en iyi alternatif olmalıdır [32].

Eğer 1. koşul sağlanmaz ve $Q\left(a^{(m)}\right)-Q\left(a^{\prime}\right) \leq D Q$ olursa, $a^{(m)}$ ve $a$ ' aynı uzlaştırıcı çözüm olur.

Eğer 2. koşul kabul edilmez ve her ne kadar $a$ '‘nın nispi bir avantajı olsa da, karar vermede tutarsızlık vardır. Bundan dolayı $a$ 've $a$ " 'nın uzlaştırıcı çözümleri aynıdır.

Adım 11: "Q" değeri minimum olan en iyi alternatifi seçilir.

\section{BULANIK TOPSIS YÖNTEMi}

TOPSIS (Technique For Order Preference By Similarity To An Ideal Solution) yöntemi, çok kriterli karar verme problemleri için ilk kez 1981 yılında önerilmiştir (Hwang ve Yoon, 1981). Bu yöntem, pozitif ideal çözüme en yakın ve negatif ideal çözüme en uzak olan alternatifleri belirler ve buna göre bir sıralama yapar (Chen, 2000). Bu yöntemin mantığı, dilsel olarak ifade edilen değerlendirmelerin bulanıklaştırılarak analizde kullanılmasına dayanmaktadır. Bulanık TOPSIS yönteminde ilk beş adım, bulanık ViKOR yöntemiyle aynıdır. Yöntemin farklılaştığı altıncı adımdan itibaren izlenen yol ise aşağıda adımlar halinde sıralanmıştır: 
Adım 6: Bulanık ViKOR yönteminin 5. adımında hesaplanmış olan bulanık karar matrisinden hareketle, normalize edilmiş bulanık karar matrisi elde edilir. Bu matris, (15) ile gösterilmiştir (Chen, 2000).

$$
\begin{aligned}
& R=\left[r_{i j}\right]_{m x n} \quad i=1,2, \ldots, m ; j=1,2, \ldots, n \\
& \tilde{r}_{\mathrm{ij}}=\left(\frac{\mathrm{a}_{\mathrm{ij}}}{\mathrm{c}_{\mathrm{j}}^{*}}, \frac{\mathrm{b}_{\mathrm{ij}}}{\mathrm{c}_{\mathrm{j}}^{*}}, \frac{\mathrm{c}_{\mathrm{ij}}}{\mathrm{c}_{\mathrm{j}}^{*}}\right), \quad \mathrm{j} \in \mathrm{B} \\
& \mathrm{c}_{\mathrm{j}}^{*}=\max _{i} \mathrm{c}_{\mathrm{ij}} \text { Eger } j \in \mathrm{B}
\end{aligned}
$$

Burada, normalize edilmiş bulanık karar matrisi,

$\mathrm{c}_{\mathrm{j}}^{*}$ : Bulanık karar matrisinde bir sütunundaki üçüncü bileşenlerin maksimum değeri,

$\tilde{r}_{\mathrm{ij}}$ : Bulanık karar matrisindeki her bir değerin $\mathrm{c}_{\mathrm{j}}^{*}$ değerine bölünmesiyle elde edilen normalize edilmiş değerleridir.

Her bir a, b, c ise bulanık karar matrisindeki değerlerdir.

Adım 7: Her bir kriterin ağırlığı göz önünde bulundurularak ağırlıklı normalize edilmiş bulanık karar matrisi (17) bulunur.

$$
\begin{aligned}
& \tilde{V}=\left[\tilde{v}_{\mathrm{ij}}\right]_{\mathrm{mxn}} \mathrm{i}=1,2, \ldots, \mathrm{m} ; \mathrm{j}=1,2, \ldots, \mathrm{n} \\
& \tilde{v}_{\mathrm{ij}}=\tilde{r}_{\mathrm{ij}}(.) \tilde{w}_{\mathrm{j}}
\end{aligned}
$$

Burada, $\tilde{V}$ normalize edilmiş bulanık karar matrisidir.

Adım 8: Her bir alternatifin Bulanık Pozitif Ideal Çözüm (BPiç, $A^{*}$ ) (19) ve Bulanık Negatif İdeal Çözüm (BNiç, $\left.A^{-}\right)(20)$ den uzaklığı sırasıyla aşağıdaki formüller kullanılarak hesaplanır (Chen, 2000).

$$
\begin{aligned}
& \mathrm{A}^{*}=\left(\tilde{v}_{1}^{*}, \tilde{v}_{2}^{*}, \ldots, \tilde{v}_{\mathrm{n}}^{*}\right), \\
& \mathrm{A}^{-}=\left(\tilde{v}_{1}^{-}, \tilde{v}_{2}^{-}, \ldots, \tilde{v}_{\mathrm{n}}^{-}\right),
\end{aligned}
$$

ile tanımlanır.

$$
\begin{aligned}
& \tilde{v}_{j}^{*}=\max _{i} v_{i j} \text { Ĕger } j \in \mathrm{B} \\
& \tilde{v}_{j}^{*}=\min _{i} v_{i j} \text { Ĕger } j \in \mathrm{B}
\end{aligned}
$$

Her bir alternatifin BPiÇ ve BNiç' ten uzaklığı sırasıyla (21) ve (22) numaralı formüller kullanılarak hesaplanır.

$$
\begin{aligned}
& \mathrm{d}_{\mathrm{j}}^{*}=\sum_{\mathrm{j}=1}^{\mathrm{n}} \mathrm{d}\left(\tilde{v}_{\mathrm{ij}}, \tilde{v}_{\mathrm{j}}^{*}\right), \mathrm{i}=1,2, \ldots, \mathrm{m} \\
& \mathrm{d}_{\mathrm{j}}^{-}=\sum_{\mathrm{j}=1}^{\mathrm{n}} \mathrm{d}\left(\tilde{v}_{\mathrm{ij}}, \tilde{v}_{\mathrm{j}}^{-}\right), \quad \mathrm{i}=1,2, \ldots, \mathrm{m}
\end{aligned}
$$

Burada $d(.,$.$) , iki üçgen bulanık sayı arasındaki$ uzaklığı gösterir. Bu uzaklık, vertex yöntemi ile bulunur. Bu yöntem ile " $m$ " ve " $n$ " arasındaki uzaklığın bulunmasında (23 numaralı formül) kullanılır (Chen, 2000).

$$
\begin{aligned}
& \tilde{m}=\left(m_{1}, m_{2}, m_{3}\right) \text { ve } \tilde{n}=\left(n_{1}, n_{2}, n_{3}\right) \\
& \mathrm{d}(\tilde{m}, \tilde{n})=\sqrt{\frac{1}{3}\left[\left(m_{1}-n_{1}\right)^{2}+\left(m_{2}-n_{2}\right)^{2}+\left(m_{3}-n_{3}\right)^{2}\right]}
\end{aligned}
$$

Adım 9: Uzaklıkların bulunmasından sonra adayların yakınlık katsayıları,

$$
\mathrm{CC}_{\mathrm{i}}=\frac{\mathrm{d}_{\mathrm{i}}^{-}}{\mathrm{d}_{\mathrm{i}}^{*}+\mathrm{d}_{\mathrm{i}}^{-}} \quad \mathrm{i}==1,2,3, \ldots, \mathrm{m}
$$

(24) numaralı eşitlik kullanılarak hesaplanır. Açıktır ki; yakınlık katsayısı (CC) 1'e yaklaştıkça $A_{i}$ alternatifi, BNiç' ten uzaklaşıp BPiÇ' e yaklaşır. Diğer bir ifadeyle; yakınlık katsayılarına göre bir sıralama yapılır ve set içerisinden en uygun alternatifler seçilir (Chen, 2000). Yakınlık katsayısı 1'e ne kadar yakınsa alternatifin tercih edilme şansı o kadar yüksektir (Ecer, 2006).

\section{KURULUŞ YERI SEÇIM PROBLEMINE YÖNELIK BIR UYGULAMA}

Bu çalışmada, Erzincan Il'inde yeni bir AVM açılmasına karar verilmesi durumunda olası kuruluş yerinin belirlenmesine çalışılmıştır. AVM kuruluş yeri seçim probleminin çözümü için bulanık ortamlarda grup karar vermeye olanak sağlayan yöntemler arasında en çok tercih edilenlerden Bulanık TOPSIS ve Bulanık ViKOR yöntemleriyle, potansiyel bölgelerin değerlendirilmesi ve bunun sonucunda en uygun yer seçilmesi hedeflenmektedir. Erzincan'daki mevcut AVM'lerin hem kapasitelerinin sınırlı olması hem de şehrin merkezinde kalmaları nedeniyle yeni bir AVM açılması düşünülmektedir. Bu çerçevede, karar vericilerle yapılan görüşmeler sonucunda 5 tane bölge ve bölgelerin değerlendirilmesi için 14 kriter belirlenmiştir. Bu kriterler Şekil 2'de gösterilmiştir. Alternatif bölgeler; $A_{1}$ : Şehir Merkezi, $A_{2}$ : Erzincan-Sivas Yolu Çevresi, $A_{3}$ : Tren İstasyonu Bölgesi, $A_{4}$ : Demirkent Bölgesi, $A_{5}$ : Akyazı Bölgesi şeklinde belirlenmiştir. Karar vericiler ise, Erzincan Ticaret Odası Başkanı (KV) , Işadamı Müteahhit (Erzincan Evim Kur Sahibi) $\left(\mathrm{KV}_{2}\right)$, Erzincan Erimpaş AVM Sahibi $\left(\mathrm{KV}_{3}\right)$ ve Erzincan Belediye Başkanı Danışmanı'ndan $\left(\mathrm{KV}_{4}\right)$ oluşan 4 kişilik bir karar verici grubu oluşturulmuştur.

Şekil 2'de uygulamaya konu olan AVM kuruluş yeri seçimi probleminin genel yapısı gösterilmektedir. AVM yer seçim probleminin çözümünde kullanılan Bulanık ViKOR ve BulanıkTOPSIS yöntemlerinin ilk beş aşaması, karar verici grubunun oluşturulması, alternatiflerin ve değerlendirme kriterlerinin belirlenmesi, kriter ağırlıkları ve alternatifler için dilsel değişkenlerin belirlenmesi, bulanık ağırlıkların hesaplanması, bulanık karar matrisinin oluşturulması açısından aynı olmakla birlikte, altıncı aşamadan itibaren yöntemler 
farklılaşmaktadır. Bulanık TOPSIS yönteminde yedinci aşamadan itibaren, normalize edilmiş bulanık karar matrislerinin elde edilmesi, ağırlıklı normalize bulanık karar matrisinin hesaplanması, her bir alternatif için bulanık pozitif ideal çözüm ve bulanık negatif ideal çözüm arası uzaklığın hesaplanması, yakınlık katsayılarının hesaplanması, en uygun yakınlık katsayısına ait alternatifin seçilmesi aşamaları takip edilmekte iken, Bulanık ViKOR yönteminde yedinci aşamadan itibaren sırasıyla; tüm kriter fonksiyonlarının en iyi ve en kötü değerlerinin belirlenmesi, bulanık en iyi ve en kötü değerlere uzaklık değerlerinin hesaplanması, diğer hesaplamaların yapılması, bulanık sayıların durulaştırılması, kabul koşullarının kontrol edilmesi ve " $Q$ " değeri en küçük alternatifin seçilmesi aşamaları izlenmektedir.

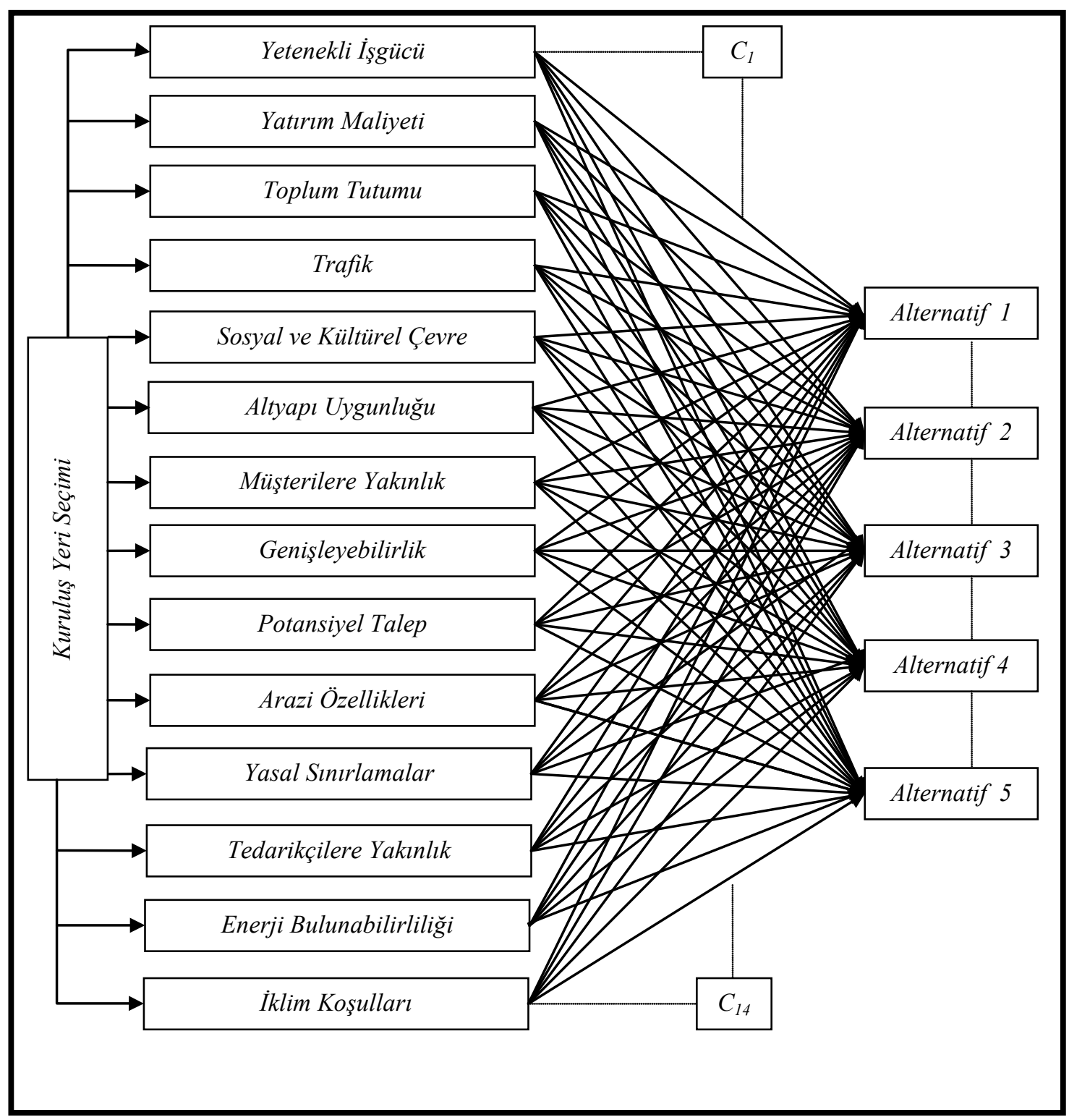

Şekil 2: AVM Kuruluş Yeri Seçim Probleminin Genel Yapısı 


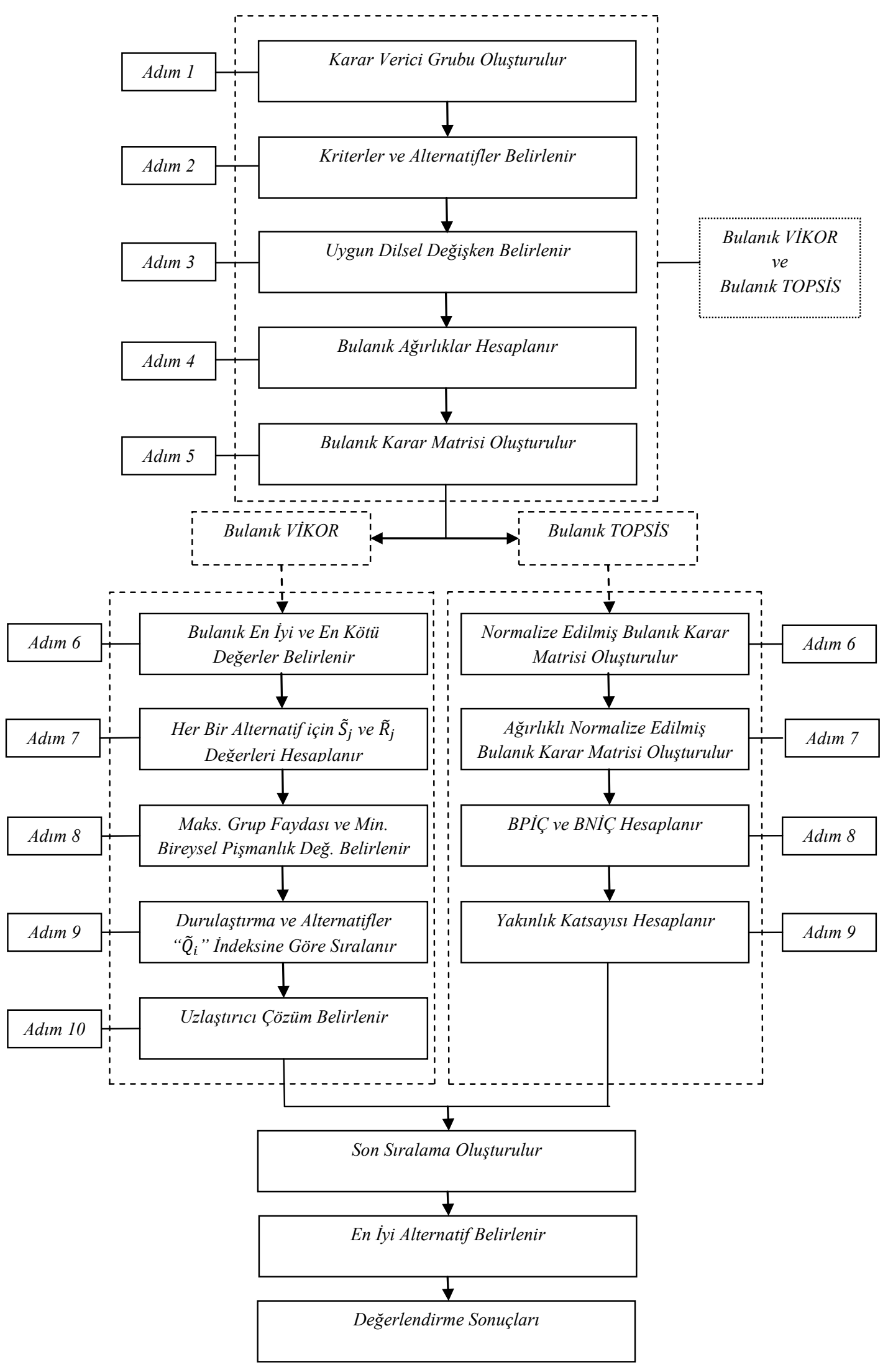

Şekil 3: Bulanık TOPSIS ve Bulanık VIKOR Yöntemlerinin Çözüm Aşamaları 


\section{BULANIK TOPSIS YÖNTEMIYLE PROBLEM ÇÖZÜMÜ}

Adım 1: Alternatifler ve alternatifleri değerlendirmek için kullanılan kriterler hakkında bilgi sahibi olan " $\mathrm{n}$ " sayıda uzman kişiden oluşan bir karar verici grubu oluşturulur.

Adım 2: "k" adet değerlendirme kriteri ve "m" adet alternatif belirlenir.

Adım 3: Tablo 2'de verilen dilsel değişkenlere göre karar vericiler tarafından doldurulan formlar; kriterlerin önem düzeyi ve her bir alternatif için kriterler bazında yapılan dilsel değerlendirmeler Ek-1 ve Ek-2'de verilmiştir.

Adım 4: Her bir kriterin ve alternatifin bulanık ağırIıkları 1. ve 2. formüllerle hesaplanır. Tablo 3'te bulanık ağırlık matrisi gösterilmiştir. Ayrıca Ek-3'te ilk sekiz kriter için bulanık ağırlıkların nasıl hesaplandığı gösterilmiştir.

Tablo 3: Kriterlerin Bulanık Ağırlık Matrisi

\begin{tabular}{|c|c|c|c|c|c|c|c|}
\hline \multicolumn{7}{|c|}{ Bulanık Ağırlıklar } \\
\hline Kriterler & $\mathrm{I}$ & $\mathrm{m}$ & $\mathrm{u}$ & Kriterler & $\mathrm{I}$ & $\mathrm{m}$ & $\mathrm{u}$ \\
\hline $\mathrm{C}_{1}$ & 0,4 & 0,6 & 0,8 & $\mathrm{C}_{8}$ & 0,35 & 0,55 & 0,75 \\
\hline $\mathrm{C}_{2}$ & 0,4 & 0,6 & 0,8 & $\mathrm{C}_{9}$ & 0,75 & 0,9 & 0,975 \\
\hline $\mathrm{C}_{3}$ & 0,55 & 0,75 & 0,9 & $\mathrm{C}_{10}$ & 0,6 & 0,8 & 0,95 \\
\hline $\mathrm{C}_{4}$ & 0,65 & 0,85 & 0,98 & $\mathrm{C}_{11}$ & 0,55 & 0,75 & 0,93 \\
\hline $\mathrm{C}_{5}$ & 0,8 & 0,95 & 1,00 & $\mathrm{C}_{12}$ & 0,4 & 0,6 & 0,8 \\
\hline $\mathrm{C}_{6}$ & 0,75 & 0,93 & 1,00 & $\mathrm{C}_{13}$ & 0,4 & 0,6 & 0,8 \\
\hline $\mathrm{C}_{7}$ & 0,4 & 0,6 & 0,8 & $\mathrm{C}_{14}$ & 0,55 & 0,75 & 0,93 \\
\hline
\end{tabular}

Adım 5: 3. ve 4. formüller yardımıyla her bir kriterin, " $A$ " alternatife göre bulanık karar matrisi oluşturulur. Tablo 4'te bulanık karar matrisi gösterilmiştir. . Ayrıca Ek-4'te $C_{1 \text { ve }} C_{2}$ kriterleri için bulanık karar matrisinin nasıl hesaplandığı gösterilmiştir.
Adım 6: Bulanık karar matrisinden faydalanılarak, 15. ve 16. numaralı formüller yardımıyla normalize edilmiş bulanık karar matrisi elde edilir. Bu matris Tablo 5'te verilmiştir.

Tablo 4: Bulanık Karar Matrisi

\begin{tabular}{|c|c|c|c|c|c|c|c|c|c|c|c|c|c|c|c|}
\hline \multirow{3}{*}{ Kriterler } & \multicolumn{15}{|c|}{ Kriterlerin Alternatiflere Göre Bulanık Karar Matrisi } \\
\hline & \multicolumn{3}{|c|}{$A_{1}$} & \multicolumn{3}{|c|}{$\mathrm{A}_{2}$} & \multicolumn{3}{|c|}{$\mathrm{A}_{3}$} & \multicolumn{3}{|c|}{$\mathrm{A}_{4}$} & \multicolumn{3}{|c|}{$\mathrm{A}_{5}$} \\
\hline & I & $\mathrm{m}$ & u & I & $\mathrm{m}$ & $\mathrm{u}$ & I & $\mathrm{m}$ & u & 1 & $\mathrm{~m}$ & $\mathrm{u}$ & I & $\mathrm{m}$ & $\mathrm{u}$ \\
\hline $\mathrm{C}_{1}$ & 6,0 & 8,0 & 9,3 & 8,0 & 9,5 & 10 & 5,0 & 7,0 & 8,5 & 7,0 & 9,0 & 10 & 7,5 & 9,3 & 10 \\
\hline $\mathrm{C}_{2}$ & 4,0 & 6,0 & 8,0 & 7,0 & 8,8 & 9,8 & 3,5 & 5,5 & 7,5 & 5,0 & 7,0 & 9,0 & 6,0 & 8,0 & 9,5 \\
\hline $\mathrm{C}_{3}$ & 6,5 & 8,3 & 9,3 & 9,0 & 10,0 & 10 & 8,0 & 9,5 & 10 & 8,0 & 9,5 & 10 & 9,0 & 10 & 10 \\
\hline $\mathrm{C}_{4}$ & 4,5 & 6,5 & 8,3 & 9,0 & 10,0 & 10 & 6,0 & 8,0 & 9,3 & 9,0 & 10 & 10 & 9,0 & 10 & 10 \\
\hline$C_{5}$ & 3,0 & 5,0 & 7,0 & 5,0 & 7,0 & 8,8 & 1,5 & 3,0 & 5,0 & 2,8 & 4,5 & 6,5 & 4,0 & 6,0 & 8,0 \\
\hline$C_{6}$ & 8,0 & 9,5 & 10 & 6,5 & 8,5 & 9,8 & 7,5 & 9,3 & 10 & 5,5 & 7,5 & 9,3 & 6,0 & 8,0 & 9,5 \\
\hline$C_{7}$ & 9,0 & 10 & 10 & 7,0 & 8,5 & 9,3 & 8,0 & 9,5 & 10 & 5,5 & 7,5 & 9,0 & 6,0 & 8,0 & 9,3 \\
\hline$C_{8}$ & 4,5 & 6,5 & 8,3 & 9,0 & 10,0 & 10 & 6,5 & 8,5 & 9,8 & 9,0 & 10 & 10 & 9,0 & 10 & 10 \\
\hline$C_{9}$ & 3,5 & 5,5 & 7,5 & 8,0 & 9,5 & 10 & 3,0 & 5,0 & 7,0 & 5,5 & 7,5 & 9,3 & 6,5 & 8,5 & 9,8 \\
\hline$C_{10}$ & 7,0 & 8,5 & 9,3 & 9,0 & 10,0 & 10 & 8,0 & 9,5 & 10 & 9,0 & 10 & 10 & 9,0 & 10 & 10 \\
\hline$C_{11}$ & 5,0 & 7,0 & 8,8 & 8,0 & 9,5 & 10 & 5,0 & 7,0 & 8,5 & 7,0 & 9,0 & 10 & 7,5 & 9,3 & 10 \\
\hline$C_{12}$ & 2,0 & 4,0 & 6,0 & 9,0 & 10,0 & 10 & 6,0 & 8,0 & 9,5 & 8,0 & 9,5 & 10 & 8,5 & 9,8 & 10 \\
\hline$C_{13}$ & 8,0 & 9,5 & 10 & 6,0 & 8,0 & 9,5 & 7,5 & 9,3 & 10 & 3,5 & 5,5 & 7,5 & 5,0 & 7,0 & 8,8 \\
\hline$C_{14}$ & 7,0 & 9,0 & 10 & 6,0 & 8,0 & 9,5 & 7,0 & 9,0 & 10 & 5,0 & 7,0 & 9,0 & 5,5 & 7,5 & 9,3 \\
\hline
\end{tabular}


Tablo 5: Normalize Edilmiş Bulanık Karar Matrisi

\begin{tabular}{|c|c|c|c|c|c|c|c|c|c|c|c|c|c|c|c|}
\hline & \multicolumn{10}{|c|}{ Kriterlerin Alternatiflere Göre Normalize Edilmiş Bulanık Karar Matrisi } \\
\cline { 2 - 16 } & \multicolumn{3}{|c|}{$\mathrm{A}_{1}$} & \multicolumn{3}{|c|}{$\mathrm{A}_{2}$} & \multicolumn{3}{c|}{$\mathrm{A}_{3}$} & \multicolumn{3}{c|}{$\mathrm{A}_{4}$} & \multicolumn{3}{c|}{$\mathrm{A}_{5}$} \\
\cline { 2 - 18 } & $\mathrm{I}$ & $\mathrm{m}$ & $\mathrm{u}$ & $\mathrm{I}$ & $\mathrm{m}$ & $\mathrm{u}$ & $\mathrm{I}$ & $\mathrm{m}$ & $\mathrm{u}$ & $\mathrm{I}$ & $\mathrm{m}$ & $\mathrm{u}$ & $\mathrm{I}$ & $\mathrm{m}$ & $\mathrm{u}$ \\
\hline $\mathrm{C}_{1}$ & 0,60 & 0,80 & 0,93 & 0,80 & 0,95 & 1,00 & 0,50 & 0,70 & 0,85 & 0,70 & 0,90 & 1,00 & 0,75 & 0,93 & 1,00 \\
\hline $\mathrm{C}_{2}$ & 0,41 & 0,62 & 0,82 & 0,72 & 0,90 & 1,00 & 0,36 & 0,56 & 0,77 & 0,51 & 0,72 & 0,92 & 0,62 & 0,82 & 0,97 \\
\hline $\mathrm{C}_{3}$ & 0,65 & 0,83 & 0,93 & 0,90 & 1,00 & 1,00 & 0,80 & 0,95 & 1,00 & 0,80 & 0,95 & 1,00 & 0,90 & 1,00 & 1,00 \\
\hline $\mathrm{C}_{4}$ & 0,45 & 0,65 & 0,83 & 0,90 & 1,00 & 1,00 & 0,60 & 0,80 & 0,93 & 0,90 & 1,00 & 1,00 & 0,90 & 1,00 & 1,00 \\
\hline $\mathrm{C}_{5}$ & 0,34 & 0,57 & 0,80 & 0,57 & 0,80 & 1,00 & 0,17 & 0,34 & 0,57 & 0,31 & 0,51 & 0,74 & 0,46 & 0,69 & 0,91 \\
\hline $\mathrm{C}_{6}$ & 0,80 & 0,95 & 1,00 & 0,65 & 0,85 & 0,98 & 0,75 & 0,93 & 1,00 & 0,55 & 0,75 & 0,93 & 0,60 & 0,80 & 0,95 \\
\hline $\mathrm{C}_{7}$ & 0,90 & 1,00 & 1,00 & 0,70 & 0,85 & 0,93 & 0,80 & 0,95 & 1,00 & 0,55 & 0,75 & 0,90 & 0,60 & 0,80 & 0,93 \\
\hline $\mathrm{C}_{8}$ & 0,45 & 0,65 & 0,83 & 0,90 & 1,00 & 1,00 & 0,65 & 0,85 & 0,98 & 0,90 & 1,00 & 1,00 & 0,90 & 1,00 & 1,00 \\
\hline $\mathrm{C}_{9}$ & 0,35 & 0,55 & 0,75 & 0,80 & 0,95 & 1,00 & 0,30 & 0,50 & 0,70 & 0,55 & 0,75 & 0,93 & 0,65 & 0,85 & 0,98 \\
\hline $\mathrm{C}_{10}$ & 0,70 & 0,85 & 0,93 & 0,90 & 1,00 & 1,00 & 0,80 & 0,95 & 1,00 & 0,90 & 1,00 & 1,00 & 0,90 & 1,00 & 1,00 \\
\hline $\mathrm{C}_{11}$ & 0,50 & 0,70 & 0,88 & 0,80 & 0,95 & 1,00 & 0,50 & 0,70 & 0,85 & 0,70 & 0,90 & 1,00 & 0,75 & 0,93 & 1,00 \\
\hline $\mathrm{C}_{12}$ & 0,20 & 0,40 & 0,60 & 0,90 & 1,00 & 1,00 & 0,60 & 0,80 & 0,95 & 0,80 & 0,95 & 1,00 & 0,85 & 0,98 & 1,00 \\
\hline $\mathrm{C}_{13}$ & 0,80 & 0,95 & 1,00 & 0,60 & 0,80 & 0,95 & 0,75 & 0,93 & 1,00 & 0,35 & 0,55 & 0,75 & 0,50 & 0,70 & 0,88 \\
\hline $\mathrm{C}_{14}$ & 0,70 & 0,90 & 1,00 & 0,60 & 0,80 & 0,95 & 0,70 & 0,90 & 1,00 & 0,50 & 0,70 & 0,90 & 0,55 & 0,75 & 0,93 \\
\hline
\end{tabular}

Adım 7: Her bir kriterin ağırlığı göz önünde bulundurularak ağırlıklı normalize edilmiş bulanık karar matrisi 17. ve 18. formüllerle bulunur. Tablo 6'da ağırlıklı normalize edilmiş bulanık karar matrisi gösterilmiştir.

Tablo 6: Ağırlıklı Normalize Edilmiş Bulanık Karar Matrisi

\begin{tabular}{|c|c|c|c|c|c|c|c|c|c|c|c|c|c|c|c|}
\hline & \multicolumn{15}{|c|}{ Kriterlerin Alternatiflere Göre Ağırlıklı Normalize Edilmiş Bulanık Karar Matrisi } \\
\hline & \multicolumn{3}{|c|}{$A_{1}$} & \multicolumn{3}{|c|}{$\mathrm{A}_{2}$} & \multicolumn{3}{|c|}{$\mathrm{A}_{3}$} & \multicolumn{3}{|c|}{$\mathrm{A}_{4}$} & \multicolumn{3}{|c|}{$\mathrm{A}_{5}$} \\
\hline & I & $\mathrm{m}$ & u & I & $\mathrm{m}$ & u & I & $\mathrm{m}$ & u & I & $\mathrm{m}$ & $\mathrm{u}$ & I & $\mathrm{m}$ & u \\
\hline $\mathrm{C}_{1}$ & 0,24 & 0,48 & 0,74 & 0,32 & 0,57 & 0,80 & 0,20 & 0,42 & 0,68 & 0,28 & 0,54 & 0,80 & 0,30 & 0,56 & 0,80 \\
\hline$C_{2}$ & 0,16 & 0,37 & 0,66 & 0,29 & 0,54 & 0,80 & 0,14 & 0,34 & 0,62 & 0,21 & 0,43 & 0,74 & 0,25 & 0,49 & 0,78 \\
\hline$C_{3}$ & 0,36 & 0,62 & 0,83 & 0,50 & 0,75 & 0,90 & 0,44 & 0,71 & 0,90 & 0,44 & 0,71 & 0,90 & 0,50 & 0,75 & 0,90 \\
\hline $\mathrm{C}_{4}$ & 0,29 & 0,55 & 0,80 & 0,59 & 0,85 & 0,98 & 0,39 & 0,68 & 0,90 & 0,59 & 0,85 & 0,98 & 0,59 & 0,85 & 0,98 \\
\hline$C_{5}$ & 0,27 & 0,54 & 0,80 & 0,46 & 0,76 & 1,00 & 0,14 & 0,33 & 0,57 & 0,25 & 0,49 & 0,74 & 0,37 & 0,65 & 0,91 \\
\hline$C_{6}$ & 0,60 & 0,88 & 1,00 & 0,49 & 0,79 & 0,98 & 0,56 & 0,86 & 1,00 & 0,41 & 0,69 & 0,93 & 0,45 & 0,74 & 0,95 \\
\hline$C_{7}$ & 0,36 & 0,60 & 0,80 & 0,28 & 0,51 & 0,74 & 0,32 & 0,57 & 0,80 & 0,22 & 0,45 & 0,72 & 0,24 & 0,48 & 0,74 \\
\hline $\mathrm{C}_{8}$ & 0,16 & 0,36 & 0,62 & 0,32 & 0,55 & 0,75 & 0,23 & 0,47 & 0,73 & 0,32 & 0,55 & 0,75 & 0,32 & 0,55 & 0,75 \\
\hline$C_{9}$ & 0,26 & 0,50 & 0,73 & 0,60 & 0,86 & 0,98 & 0,23 & 0,45 & 0,68 & 0,41 & 0,68 & 0,90 & 0,49 & 0,77 & 0,95 \\
\hline$C_{10}$ & 0,42 & 0,68 & 0,88 & 0,54 & 0,80 & 0,95 & 0,48 & 0,76 & 0,95 & 0,54 & 0,80 & 0,95 & 0,54 & 0,80 & 0,95 \\
\hline$C_{11}$ & 0,28 & 0,53 & 0,81 & 0,44 & 0,71 & 0,93 & 0,28 & 0,53 & 0,79 & 0,39 & 0,68 & 0,93 & 0,41 & 0,69 & 0,93 \\
\hline$C_{12}$ & 0,08 & 0,24 & 0,48 & 0,36 & 0,60 & 0,80 & 0,24 & 0,48 & 0,76 & 0,32 & 0,57 & 0,80 & 0,34 & 0,59 & 0,80 \\
\hline$C_{13}$ & 0,32 & 0,57 & 0,80 & 0,24 & 0,48 & 0,76 & 0,30 & 0,56 & 0,80 & 0,14 & 0,33 & 0,60 & 0,20 & 0,42 & 0,70 \\
\hline$C_{14}$ & 0,39 & 0,68 & 0,93 & 0,33 & 0,60 & 0,88 & 0,39 & 0,68 & 0,93 & 0,28 & 0,53 & 0,83 & 0,30 & 0,56 & 0,86 \\
\hline
\end{tabular}

Adım 8: Her bir alternatifin Bulanık Pozitif İdeal Çözüm (BPiÇ, ) ve Bulanık Negatif İdeal Çözüm (BNiç, ) kümeleri sırasıyla 19. ve 20. formüller kullanılarak hesaplanır. Tablo 7'de ağırlıklı normalize edilmiş bulanık karar matrisi gösterilmiştir. 
Tablo 7: Bulanık Pozitif ve Bulanık Negatif İdeal Çözüm (BPiç \& BNiÇ)

\begin{tabular}{|c|c|c|c|c|c|c|c|c|c|c|}
\hline & \multicolumn{10}{|c|}{ BPiÇ \& BNiç } \\
\cline { 2 - 12 } & $\mathrm{A}_{1^{\prime}} \mathrm{A}^{*}$ & $\mathrm{~A}_{2^{\prime}} \mathrm{A}^{*}$ & $\mathrm{~A}_{3^{\prime}} \mathrm{A}^{*}$ & $\mathrm{~A}_{4^{\prime}} \mathrm{A}^{*}$ & $\mathrm{~A}_{5^{\prime}} \mathrm{A}^{*}$ & $\mathrm{~A}_{1^{\prime}} \mathrm{A}^{-}$ & $\mathrm{A}_{2^{\prime}} \mathrm{A}^{-}$ & $\mathrm{A}_{3^{\prime}} \mathrm{A}^{-}$ & $\mathrm{A}_{4^{\prime}} \mathrm{A}^{-}$ & $\mathrm{A}_{5^{\prime}} \mathrm{A}^{-}$ \\
\hline $\mathrm{C}_{1}$ & 0,55 & 0,48 & 0,60 & 0,51 & 0,49 & 0,53 & 0,60 & 0,48 & 0,58 & 0,59 \\
\hline $\mathrm{C}_{2}$ & 0,64 & 0,50 & 0,66 & 0,58 & 0,54 & 0,45 & 0,58 & 0,41 & 0,51 & 0,55 \\
\hline $\mathrm{C}_{3}$ & 0,44 & 0,33 & 0,37 & 0,37 & 0,33 & 0,63 & 0,73 & 0,71 & 0,71 & 0,73 \\
\hline $\mathrm{C}_{4}$ & 0,50 & 0,26 & 0,40 & 0,26 & 0,26 & 0,59 & 0,82 & 0,69 & 0,82 & 0,82 \\
\hline $\mathrm{C}_{5}$ & 0,51 & 0,34 & 0,68 & 0,54 & 0,42 & 0,58 & 0,77 & 0,39 & 0,53 & 0,68 \\
\hline $\mathrm{C}_{6}$ & 0,24 & 0,32 & 0,27 & 0,38 & 0,35 & 0,84 & 0,78 & 0,83 & 0,71 & 0,74 \\
\hline $\mathrm{C}_{7}$ & 0,45 & 0,52 & 0,48 & 0,57 & 0,55 & 0,61 & 0,54 & 0,60 & 0,51 & 0,53 \\
\hline $\mathrm{C}_{8}$ & 0,65 & 0,49 & 0,56 & 0,49 & 0,49 & 0,42 & 0,57 & 0,52 & 0,57 & 0,57 \\
\hline$C_{9}$ & 0,54 & 0,25 & 0,58 & 0,39 & 0,33 & 0,53 & 0,82 & 0,49 & 0,69 & 0,76 \\
\hline$C_{10}$ & 0,39 & 0,29 & 0,33 & 0,29 & 0,29 & 0,69 & 0,78 & 0,76 & 0,78 & 0,78 \\
\hline$C_{11}$ & 0,51 & 0,37 & 0,52 & 0,40 & 0,38 & 0,58 & 0,72 & 0,57 & 0,70 & 0,71 \\
\hline$C_{12}$ & 0,75 & 0,45 & 0,55 & 0,48 & 0,46 & 0,31 & 0,61 & 0,54 & 0,60 & 0,60 \\
\hline$C_{13}$ & 0,48 & 0,55 & 0,49 & 0,67 & 0,60 & 0,60 & 0,54 & 0,59 & 0,40 & 0,49 \\
\hline$C_{14}$ & 0,40 & 0,46 & 0,40 & 0,51 & 0,48 & 0,70 & 0,64 & 0,70 & 0,59 & 0,62 \\
\hline
\end{tabular}

Her bir alternatifin BPiç ve BNiç' ten uzaklığı sırasıyla 21. ve 22. formüllerle hesaplanmıştır. Uzaklıkların bulunmasından sonra adayların yakınlık katsayıları (23) numaralı formülle hesaplanmıştır. Karar vericilerin verdikleri bilgiler doğrultusunda, Bulanık TOPSIS yöntemiyle çözüm neticesinde, alternatifler arasında ortaya çıkan sıralama Tablo 8'de gösterilmiştir. Buna göre; $A_{2}$ bölgesi 1.sırada ve $A_{5}$ bölgesi ise 2.sırada yer almıştır.

Tablo 8: Alternatiflerin İdeal Çözüme Yakınlık Katsayıları ve Sıralamaları

\begin{tabular}{|c|c|c|c|c|}
\hline Alternatifler & $\mathrm{D}^{*}$ & $\mathrm{D}^{-}$ & $\mathrm{CC}$ & Siralama \\
\hline $\mathrm{A}_{1}$ & 7,052 & 8,058 & 0,533 & 5 \\
\hline $\mathrm{A}_{2}$ & 5,610 & 9,511 & 0,629 & 1 \\
\hline $\mathrm{A}_{3}$ & 6,891 & 8,254 & 0,545 & 4 \\
\hline $\mathrm{A}_{4}$ & 6,458 & 8,695 & 0,574 & 3 \\
\hline $\mathrm{A}_{5}$ & 5,985 & 9,168 & 0,605 & 2 \\
\hline
\end{tabular}
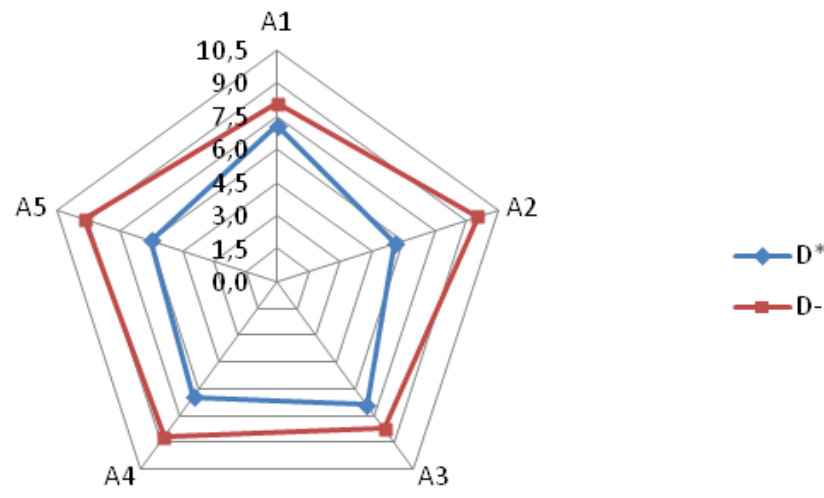

Şekil 4: AVM Yeri Seçimi İçin D* \& D- Değerlendirilmesi 


\section{BULANIK VIKOR YÖNTEMIYLE PROBLEM ÇÖZÜMÜ}

Yukarıda Bulanık TOPSIS yöntemine göre çözümü sunulan kuruluş yer seçim problemi, bu aşamada Bulanık VIKOR yöntemine göre de çözülmüştür. Daha önce de ifade ettiğimiz üzere, her iki yöntem bulanık karar matrisinin oluşturulması aşamasına kadar aynıdır. Bu nedenle Bulanık VIKOR yönteminin çözümü, yöntemlerin farklılaştığı "Adım 6"dan itibaren gösterilmiştir.

Adım 6: Tüm kriter fonksiyonlarının, bulanık en iyi $\left(\tilde{f}_{i}^{*}\right)(5)$ ve en kötü değerleri $\left(\tilde{f}_{i}^{-}\right)(6)$ no'lu formüllerle hesaplanmış ve Tablo 9'da gösterilmiştir.

Tablo 9: Kriterlerin Bulanık En İyi ve Bulanık En Değerler

\begin{tabular}{|c|c|c|c|c|c|c|}
\hline \multirow{2}{*}{} & \multicolumn{3}{|c|}{$\tilde{f}_{i}^{*}$} & \multicolumn{3}{c|}{$\tilde{f}_{i}^{-}$} \\
\cline { 2 - 7 } & $\mathrm{I}$ & $\mathrm{m}$ & $\mathrm{u}$ & $\mathrm{I}$ & $\mathrm{m}$ & $\mathrm{u}$ \\
\hline $\mathrm{C}_{1}$ & 8 & 9,5 & 10 & 5 & 7 & 8,5 \\
\hline $\mathrm{C}_{2}$ & 7 & 8,75 & 9,75 & 3,5 & 5,5 & 7,5 \\
\hline $\mathrm{C}_{3}$ & 9 & 10 & 10 & 6,5 & 8,25 & 9,25 \\
\hline $\mathrm{C}_{4}$ & 9 & 10 & 10 & 4,5 & 6,5 & 8,25 \\
\hline $\mathrm{C}_{5}$ & 5 & 7 & 8,75 & 1,5 & 3 & 5 \\
\hline $\mathrm{C}_{6}$ & 8 & 9,5 & 10 & 5,5 & 7,5 & 9,25 \\
\hline $\mathrm{C}_{7}$ & 9 & 10 & 10 & 5,5 & 7,5 & 9 \\
\hline $\mathrm{C}_{8}$ & 9 & 10 & 10 & 4,5 & 6,5 & 8,25 \\
\hline $\mathrm{C}_{9}$ & 8 & 9,5 & 10 & 3 & 5 & 7 \\
\hline $\mathrm{C}_{10}$ & 9 & 10 & 10 & 7 & 8,5 & 9,25 \\
\hline $\mathrm{C}_{11}$ & 8 & 9,5 & 10 & 5 & 7 & 8,5 \\
\hline $\mathrm{C}_{12}$ & 9 & 10 & 10 & 2 & 4 & 6 \\
\hline $\mathrm{C}_{13}$ & 8 & 9,5 & 10 & 3,5 & 5,5 & 7,5 \\
\hline $\mathrm{C}_{14}$ & 7 & 9 & 10 & 5 & 7 & 9 \\
\hline
\end{tabular}

Adım 7: $\tilde{S}_{\mathrm{i}}(7)$ ve $\tilde{R}_{\mathrm{i}}(8)$ formülleri kullanılarak her bir alternatifin en iyi bulanık ve en kötü bulanık değerlere uzaklıkları hesaplanmış ve Tablo 10'da gösterilmiştir.

Tablo 10: Alternatiflerin $\tilde{S}_{\mathrm{i}}$ ve $\tilde{R}_{\mathrm{i}}$ Değerlerinin Belirlenmesi

\begin{tabular}{|c|c|c|c|c|c|c|}
\hline \multirow{2}{*}{ Alternatifler } & \multicolumn{3}{|c|}{$\tilde{S}_{\mathrm{i}}$} & \multicolumn{3}{c|}{$\tilde{R}_{\mathrm{i}}$} \\
\cline { 2 - 7 } & $\mathrm{I}$ & $\mathrm{m}$ & $\mathrm{u}$ & $\mathrm{I}$ & $\mathrm{m}$ & $\mathrm{u}$ \\
\hline $\mathrm{A}_{1}$ & 4,842 & 6,443 & 7,447 & 0,650 & 0,850 & 0,975 \\
\hline $\mathrm{A}_{2}$ & 1,131 & 1,423 & 1,556 & 0,450 & 0,463 & 0,333 \\
\hline $\mathrm{A}_{3}$ & 4,528 & 5,476 & 5,125 & 0,800 & 0,950 & 1,000 \\
\hline $\mathrm{A}_{4}$ & 3,812 & 4,726 & 4,635 & 0,750 & 0,925 & 1,000 \\
\hline $\mathrm{A}_{5}$ & 2,377 & 2,847 & 2,731 & 0,600 & 0,694 & 0,667 \\
\hline
\end{tabular}

Adım 8: Maksimum grup faydası $\tilde{S}_{\mathrm{i}}, \tilde{S}^{*}(9)$ ve minimum bireysel pişmanlık , $\tilde{R}^{*}(10)$ formülleri kullanılarak hesaplanmış ve Tablo 11'de gösterilmiştir.

Tablo 11: $\tilde{S}_{\mathrm{i}}, \tilde{S}^{*}, \tilde{R}_{\mathrm{i}}$ ve $\tilde{R}^{*}$ Değerleri

\begin{tabular}{|c|c|c|c|}
\hline & $\mathrm{I}$ & $\mathrm{m}$ & $\mathrm{U}$ \\
\hline$\tilde{S}^{*}$ (Min.) & 1,131 & 1,423 & 1,556 \\
\hline$\tilde{S}_{\mathrm{i}}$ (Maks.) & 4,842 & 6,443 & 7,447 \\
\hline$\tilde{R}^{*}$ (Min.) & 0,450 & 0,463 & 0,333 \\
\hline$\tilde{R}_{\mathrm{i}}$ (Maks.) & 0,800 & 0,950 & 1,000 \\
\hline
\end{tabular}


Adım 9: Bu son adımda uzlaşık çözüm veren $\tilde{Q}_{\mathrm{i}}$ (11) değerleri hesaplanır. Ayrıca bulanık sayılar durulaştırılarak (12); $S_{i}$, $R_{i}$ ve $Q_{i}$ indeks değerleri bulunmustur. Elde edilen ortalama sonuçlar Tablo 12'de gösterilmiştir. Bulunan indeks değerlerine göre alternatifler arasında küçükten büyüğe doğru bir sıralama yapılmıştır. İndeks değeri en küçük olan en iyi alternatifi göstermektedir. Bu yönteme göre; $A_{2}$ bölgesi 1 . sırada ve $A_{5}$ bölgesi ise 2 . sırada yer almıştır.

Tablo 12: Alternatiflerin İndeksine Göre Sıralaması $Q_{i}$

\begin{tabular}{|c|c|c|c|c|c|c|c|c|c|}
\hline \multirow{2}{*}{$\begin{array}{c}\text { Alter- } \\
\text { natifler }\end{array}$} & \multicolumn{4}{|c|}{$Q_{i}$} & \multicolumn{2}{c|}{$Q_{i}$} & \multicolumn{2}{c|}{$S_{i}$} & \multicolumn{3}{|c|}{$R_{i}$} \\
\cline { 2 - 10 } & $\mathrm{I}$ & $\mathrm{m}$ & $\mathrm{u}$ & Indeks & Sira & Indeks & Sira & Indeks & Sira \\
\hline $\mathrm{A}_{1}$ & 0,786 & 0,897 & 0,981 & 0,888 & 4 & 6,244 & 5 & 0,825 & 4 \\
\hline $\mathrm{A}_{2}$ & 0,000 & 0,000 & 0,000 & 0,000 & 1 & 1,370 & 1 & 0,415 & 1 \\
\hline $\mathrm{A}_{3}$ & 0,958 & 0,904 & 0,803 & 0,888 & 4 & 5,043 & 4 & 0,917 & 5 \\
\hline $\mathrm{A}_{4}$ & 0,790 & 0,803 & 0,761 & 0,785 & 3 & 4,391 & 3 & 0,892 & 3 \\
\hline $\mathrm{A}_{5}$ & 0,382 & 0,379 & 0,350 & 0,370 & 2 & 2,652 & 2 & 0,653 & 2 \\
\hline
\end{tabular}

Adım 10: $A_{2}$ alternatifinin en iyi çözüm olup olmadığını test etmek için aşağıdaki iki koşulun uygunluğu kontrol edilmiştir.

1.Koşul: Kabul edilebilir avantaj

$Q\left(a^{\prime \prime}\right)-Q\left(a^{\prime}\right) \geq 0,25$ koşulu sağlanmalıdır $(0,376$ $0 \geq 0,25$ ).

$$
D Q=\frac{1}{m-1} \text { (eğer } \mathrm{m} \leq 5 \text { ise } \mathrm{DQ}=0.25 \text { ); } \mathrm{m} \text { alternatif }
$$

sayısını ifade eder )

$\mathrm{A}_{2}$ alternatifi kabul edilebilir avantaj koşulunu sağlamaktadır.

\section{Koşul: Karar vermede kabul edilebilir istikrar}

Alternatif a', S ve/veya R değerlerine göre yapılan sıralamada en iyi alternatif olmalıdır.

Eğer 1. koşul sağlanmaz ve $Q\left(a^{(m)}\right)-Q\left(a^{\prime}\right) \leq D Q$ olursa, $a^{(m)}$ ve a' aynı uzlaştırıcı çözüm olur.

Tablo 13: Karar Vermede Kabul Edilebilir İstikrar

\begin{tabular}{|l|l|}
\hline$Q_{i}$ & $A_{2}>A_{5}>A_{4}>A_{3}=A_{1}$ \\
\hline$S_{i}$ & $A_{2}>A_{5}>A_{4}>A_{3}>A_{1}$ \\
\hline$R_{i}$ & $A_{2}>A_{5}>A_{4}>A_{1}>A_{3}$ \\
\hline
\end{tabular}

Bulanık Topsis ve Vikor yöntemlerin sonuçları karşılaştırılığında; her iki yöntemde de 1. sırada $A_{2}$ bölgesi, 2. sırada $A_{5}$ bölgesi ve 3. sırada $A_{4}$ bölgesi çıkmıştır. Sadece $A_{1}$ ve $A_{3}$ alternatiflerinin sıralamalarında bir değişiklik olduğu gözlenmektedir. Bu bağlamda her iki yöntemin uygulanması sonucunda $A_{2}$ bölgesinin seçilmesi uygun görülmüştür.

\section{SONUÇ}

Müşteri beklentilerinde meydana gelen değişim; satın alma kararı üzerinde fiyat faktörünün tek ve yeter belirleyici olarak kabul görmesini ortadan kaldırmış, fiyatın yanı sıra kalite, güvenilirlik, satış sonrası hizmetler satın alma kararı üzerinde gün geçtikçe daha da fazla etkili olmaya başlamıştır. Bu bağlamda, minimum maliyetlerle işletmelerin uzun dönemli rekabetçi yapılarını destekleyecek, yüksek kârı ve müşteri memnuniyeti sağlayacak yerleri seçmek gerekir. $\mathrm{Bu}$ çalışmada, sonuçları dikkate alındığında uzun vadede geri dönülemez, dönülse dahi yüksek maliyetlere katlanılmasına neden olan ve bu nedenle ilk seferde doğru kararın verilmesini gerektiren stratejik karar türlerinden AVM yer seçimi üzerinde durulmuştur. AVM yer seçimi, pek çok faktörün birbirleriyle etkileşim halinde olduğu ve çoğu zaman arzulanan kazanımların çeliştiği durumlarda, uzlaştırıcı çözüme ulaştıracak yöntemlerin seçimi her zamankinden daha da fazla önem kazanmaktadır. Bu nedenle, çözüme ulaşmada kullanılan yöntemlerin nihai seçim kararı üzerinde etkili olan pek çok faktörü dikkate alabilen yöntemler olması gerekliliği, etkin çözüme ulaşılması açısından hayati önem taşımaktadır.

Alternatiflerin değerlendirilmesi ve en iyi olanın seçimi için; birden fazla kriter ve karar vericiye dayalı değerlendirmeleri gerektiren durumlar ile son yıllarda sıklıkla kullanılan; Çok Kriterli Karar Verme (ÇKKV) yöntemlerinden Bulanık VIKOR ve Bulanık TOPSIS yöntemleri kullanılarak çözüm için farklı bir yaklaşım sergilenmeye çalışılmıştır. Alternatiflerin değerlendirilmesi için; yetenekli işgücü, yatırım maliyeti, toplum tutumu, trafik, sosyal ve kültürel çevre, altyapı uygunluğu, müşterilere yakınlık, genişleyebilirlik, potansiyel talep, arazi özellikleri, yasal sınırlamalar ve teşvikler, tedarikçilere ve kaynaklara yakınlık, enerji ve yakıt bulunabilirliği ve iklim koşulları olmak üzere toplam 14 ktiter belirlenmiştir. Yapılan çalışma sonucunda söz konusu kriterler arasından; potansiyel talep, altyapı uygunluğu, sosyal ve kültürel çevre karar vericiler tarafından kuruluş yeri seçiminde en önemli değerlendirme kriterleri olarak kabul gördüğü belirlenmiştir. İncelenen kuruluş yeri seçim probleminin Bulanık VIKOR ve Bulanık TOPSIS yöntemleriyle çözümü neticesinde, $A_{2}$ bölgesinin diğer alternatifler arasında birinci sırada seçilmiş̧ir.

Bulanık TOPSIS ve VIKOR yöntemiyle elde edilen sonuçların sıralaması birbirine çok yakındır. Sadece bulanık VIKOR yönteminde $A_{1}$ ve $A_{3}$ alternatiflerinin sıralamalarında bir değişiklik olduğu gözlenmektedir. Bunun sebebi ise alternatiflerin sıralanması ve seçim aşamasında, maksimum grup faydası (çoğunluk kuraIı) ve minimum bireysel pişmanlığı sağlayacak uzlaştı- 
rıCı çözüm aranmasıdır. ÇKKV tekniği olan TOPSIS ve VIKOR yöntemlerinin her ikisi de "ideal çözüme yakınlık" referans noktasına dayanmaktadır. Bu iki yöntem alternatifleri sıralarken kullandığı analiz birbirinden farklıdır. VIKOR yöntemi $Q_{j}$ fonksiyonunu kullanırken, TOPSIS yöntemi ise $C_{j}$ fonksiyonunu kullanmaktadır. Bu iki ÇKKV yöntemi farklı normalizasyon tekniği kullanmaktadır. VIKOR liner normalizasyonu kullanırken TOPSIS vektör normalizasyonunu kullanmaktadır
(Opricovic ve Tzeng). Bu yöntemlerin uygulama alanı sadece kuruluş yeri seçimi ile sınırlı olmayıp, grup kararı vermeyi gerektiren tedarikçi seçimi, insan kaynakları yönetiminde personel seçimi veya performans değerleme, yatırım sektöründe, üretim yönetimi ve yönetim ve organizasyon gibi alanlarda da uygulama alanı bulabilir. 


\section{KAYNAKLAR}

Akyüz, G. (2012) "Bulanık VIKOR Yöntemi İle Tedarikçi Seçimi” Atatürk Üniversitesi İktisadi ve İdari Bilimler Dergisi, 26(1):197-215.

Alpay, M. (2010) “Kredi Değerliliğinin Ölçülmesinde TOPSIS Yöntemi ve Bir Uygulama” Yayınlanmamış Yüksek Lisans Tezi, İzmir, D.E.Ü. Sosyal Bilimler Enstitüsü.

Aydın, Ö., Öznehir, S. ve Akçalı, E. (2009) “ Ankara için Optimal Hastane Yeri Seçiminin Analitik Hiyerarşi Süreci İle Modellenmesi "Süleyman Demirel Üniversitesi İktisadi ve Ídari Bilinler Fakültesi Dergisi, 14(2): 69-86.

Aytekin, A. ve Kaygın, B. (2005) "Bilgisayar Destekli İşletme Kuruluş Yeri Seçimi” Gazi Üniversitesi Orman Fakültesi Dergisi, 25(2): 213-226.

Chen, C.T. (2000) "Extensions of the TOPSIS for Group Decision Making Under Fuzzy Environment" Fuzzy Sets and Systems, 114: 1-9.

Chen, L.Y. ve Wang, T.C. (2009) “Optimizing Partners Choice İn IS/IT Outsoutcing Projects: The Strategic Decision of Fuzzy VIKOR" International Journal of Production Economics, 120(1): 233-242.

Chou, S.Y., Chang, Y.H. ve Shen, C.Y. (2008) "A Fuzzy Simple Additive Weighting System Undergroup Decision-Making Forfacility Location Selection with Objective/Subjective Attributes" European Journal of Operational Research, 189(1): 132-145.

Chou, C.C. (2010) "Application of a Fuzzy MCDM Model to the Evaluation of Plant Location" International Journal of Innovative Computing" Information and Control, 6(6): 2581-2594.

Chu, T.C. (2002) "Facility Location Selection Using Fuzzy TOPSIS Under Group Decisions" International Journal of Uncertainty Fuzziness and Knowledge-Based Systems, 10(6):687-702.

Çınar, N.T. (2010) "Kuruluş Yeri Seçiminde Bulanık TOPSIS Yöntemi ve Bankacılık Sektöründe Bir Uygulama" KMÜ Sosyal ve Ekonomik Araştırmalar Dergisi, 12(18): 37-45.

Deluka-Tibljas, A., Karleusa, B. ve Benac, C. (2011) "AHP Methodology Application in Garage-Parking Facility Location Selection" Promet-Traffice-Transportation, 23(4): 303-313.

Demir H.H. (2010) "İmalat Sektöründe Bulanık TOPSIS Yöntemiyle Tedarikçi Seçimi” Yayınlanmamış Yüksek Lisans Tezi, İstanbul, İ. Ü. Sosyal Bilimler Enstitüsü.
Demirel, T., Demirel, N.Ç. ve Kahraman, C. (2010) "Multi-Criteri Aware House Location Selection Using Choquet İntegral" Expert Systems with Applications, 37(5): 3943-3952.

Deveci, M. ve Kuvvetli, Y. (2012) “Kuruluş Yeri Seçiminde Bulanık VIKOR Yöntemi ve Bir Uygulama” 32. Ulusal Yöneylem Araştırması ve Endüstri Mühendisliği Kongresi Bildiri Özetleri Kitabı, 75.

Doğan, I. (2012) "Analysis of Facility Location Model Using Bayesian Networks" Expert Systems with Applications: An International Journal, 39(1):1092-1104.

Ecer, F. (2006) "Bulanık Ortamlarda Grup Kararı Vermeye Yardımcı Bir Yöntem: Fuzzy Topsıs ve Bir Uygulama” İsletme Fakültesi Dergisi, 7(2), 77-96.

Ersoy, A. ve Saat, E.M. (2011) Üretim/İşlemler Yönetimi, 2.Basım, Ankara, İmaj Yayınevi.

Ertuğrul, İ. ve Karakaşoğlu, N. (2008) “Comparison of Fuzzy AHP And Fuzzy TOPSIS Methods for Facility Location Selection" The International Journal of Advanced Manufacturing Technology, 39(7): 783-795.

Hsieh, T.Y., Lu, S.T. ve Tzeng, G.H. (2004) "Fuzzy MCDM Approach for Planning and Design Tenders Selection in Public Office Buildings" International Journal of Project Management, 22(7): 573-584.

Hu, Y., Wu, S. ve Cai, L. (2009) "Fuzzy Multi-Criteria Decision-Making TOPSIS for Distribution Center Location Selection" International Conference on Networks Security, Wireless Communications and Trusted Computing IEEE, 707-710.

Hwang, C.L. ve Yoon, K. (1981) Multiple Attributes Decision Making Methods and Applications, Springer-Werlag, Berlin, Heidelberg.

Kaboli, A., Aryanezhad, M., Shahanaghi, K. ve Niroomand, I. (2007) "A New Method for Plant Location Selection Problem: A Fuzzy-AHP Approach" Systems, Man and Cybernetics, ISIC. IEEE International Conference, 582-585.

Kahraman, C., Ruan, D. ve Dogan, I. (2003) "Fuzzy Group Decision-Making Forfacility Location Selection” Information Sciences, 157: 135-153.

Kaya, I. ve Çınar, D. (2007) "Facility Location Selection Using a Fuzzy out Ranking Method" Journal Of Multıple Valued Logic And Soft Computıng, 14: 251-263. 
Kobu, B. (2008) Üretim Yönetimi, 14. Baskı, İstanbul, Beta Yayınları.

Liang, G.S. ve Mao-Jiun, J. (1991) "A Fuzzy MultiCriteria Decision-Making Method for Facility Site Selection" The International Journal of Production Research, 29(11): 2313-2330.

Michael, J.H., Teitelve, J. ve Granskog, J.E. (1998) "Production Facility Site Selection Factors for Texas Value-Added Wood Producers" Forest products journal, 48(7-8): 27-32.

Momeni, M., Fathi, M.R. ve Kashef, M. (2011) "A Fuzzy VIKOR Approach for Plant Location Selection" Journal of American Science, 7 (9):766-771.

Opricovic, S. (1998) Multi Criteria Optimization of Civil Engineering Systems, Faculty of Civil Engineering, Belgrade.

Opricovic, S. ve Tzeng, G.H. (2004) "The compromise solution by MCDM methods: A comparative analysis of VIKOR and TOPSIS" European Journal of Operational Research, 156(2): 445-455.
Opricovic, S. (2011) "Fuzzy VIKOR with an application to water resources planning" Expert Systems with Applications, 38:12983-12990.

Özdağoğlu, A. (2011) "A Multi-Criteria DecisionMaking Methodology on The Selection of Facility Location: Fuzzy ANP " The International Journal of Advanced Manufacturing Technology, 1-17.

Russell, R.S. ve Taylor, B.W. (1999) Operations Management, Third Edition, Prentice Hall.

Salehi, M. ve Tavakkoli-Moghaddam, R. (2008) "Project Selection by Using a Fuzzy TOPSIS Technique" World Academy of Science, Engineering and Technology, 40: 85-90.

Tavakkol1-Moghaddam, R., Mousavi, S. ve Heydar, M. (2011) "An Integrated AHP-VIKOR Methodology for Plant Location Selection" International Journal of Engineering, 24 (2): 127-137.

Zadeh, L.A. (1965) "Fuzzy Sets" Information and Control, 8: 338-353. 


\section{EKLER}

Ek 1: Kriterlerin Önem Düzeyi

\begin{tabular}{|c|c|c|c|c|c|c|c|c|c|c|c|c|c|c|}
\hline \multirow{2}{*}{$\begin{array}{l}\text { Karar } \\
\text { Verici }\end{array}$} & \multicolumn{14}{|c|}{ Kriterler } \\
\hline & $C_{1}$ & $C_{2}$ & $\mathrm{C}_{3}$ & $C_{4}$ & $C_{5}$ & $C_{6}$ & $C_{7}$ & $\mathrm{C}_{8}$ & $C_{9}$ & $C_{10}$ & $C_{11}$ & $C_{12}$ & $C_{13}$ & $C_{14}$ \\
\hline $\mathrm{KV}_{1}$ & OY & OY & Y & Y & ÇY & ÇY & OY & OY & Y & Y & Y & OY & OY & $Y$ \\
\hline $\mathrm{KV}_{2}$ & 0 & 0 & OY & Y & Y & Y & 0 & 0 & OY & OY & OY & 0 & 0 & OY \\
\hline $\mathrm{KV}_{3}$ & 0 & OY & 0 & OY & ÇY & Y & OY & 0 & ÇY & $Y$ & OY & OY & 0 & OY \\
\hline $\mathrm{KV}_{4}$ & OY & 0 & Y & Y & $Y$ & Y & O & O & ÇY & OY & OY & 0 & OY & OY \\
\hline
\end{tabular}

Ek 2: Kriterler Bazında Alternatiflerin Değerlendirilmesi

\begin{tabular}{|c|c|c|c|c|c|c|c|c|c|c|c|c|c|c|c|}
\hline \multirow{2}{*}{ Alternatifler } & \multirow{2}{*}{$\begin{array}{l}\text { Karar } \\
\text { Verici }\end{array}$} & \multicolumn{14}{|c|}{ Kriterler } \\
\hline & & $C_{1}$ & $C_{2}$ & $\mathrm{C}_{3}$ & $\mathrm{C}_{4}$ & $C_{5}$ & $C_{6}$ & $C_{7}$ & $C_{8}$ & $C_{9}$ & $C_{10}$ & $C_{11}$ & $C_{12}$ & $C_{13}$ & $C_{14}$ \\
\hline \multirow{4}{*}{$\begin{array}{c}A_{1} \\
\text { (Bölge 1) }\end{array}$} & $\mathrm{KV}_{1}$ & i & O & i & o & o & i & Çì & O & 0 & $i$ & i & OK & i & $i$ \\
\hline & $\mathrm{KV}_{2}$ & 0 & oil & çi & 0 & O & Çi & çi & $\mathrm{i}$ & oi & Çi & oi & O & Çí & $\mathrm{i}$ \\
\hline & $\mathrm{KV}_{3}$ & $i$ & 0 & i & oi & 0 & Çì & çì & oi & o & Çì & oi & 0 & Çì & $\mathrm{i}$ \\
\hline & $\mathrm{KV}_{4}$ & i & oi & i & $i$ & 0 & $\mathrm{i}$ & çأ & 0 & 0 & Çì & 0 & OK & i & $i$ \\
\hline \multirow{4}{*}{$\begin{array}{c}\mathrm{A}_{2} \\
\text { (Bölge 2) }\end{array}$} & $\mathrm{KV}_{1}$ & çi & i & Çi & çi & i & i & 0 & Çi & çi & çi & Çأ & çi & i & $i$ \\
\hline & $\mathrm{KV}_{2}$ & 1 & oi & çأ & çi & oi & $\mathrm{i}$ & $\mathrm{i}$ & Çi & i & çi & $i$ & çi & oi & oi \\
\hline & $\mathrm{KV}_{3}$ & çأ & $i$ & çi & çi & oi & $i$ & çأ & çأ & i & Çi & i & Çi & oi & oi \\
\hline & $\mathrm{KV}_{4}$ & i & çi & çi & çi & 0 & oi & çi & çi & Çí & Çí & çi & çi & 1 & $i$ \\
\hline \multirow{4}{*}{$\begin{array}{c}\mathrm{A}_{3} \\
\text { (Bölge 3) }\end{array}$} & $\mathrm{KV}_{1}$ & i & 0 & i & i & $\mathrm{K}$ & i & çì & i & o & Çì & i & i & i & i \\
\hline & $\mathrm{KV}_{2}$ & 0 & 0 & çi & i & 0 & i & $i$ & i & 0 & $i$ & i & oi & Çi & $\mathrm{i}$ \\
\hline & $\mathrm{KV}_{3}$ & $\mathrm{O}$ & 0 & çi & O & $\mathrm{K}$ & Çi & i & oi & 0 & $\mathrm{i}$ & 0 & $\mathrm{i}$ & $i$ & $i$ \\
\hline & $\mathrm{KV}_{4}$ & $i$ & oi & $\mathrm{i}$ & $i$ & 0 & $i$ & çi & $i$ & o & Çí & 0 & oi & i & $i$ \\
\hline \multirow{4}{*}{$\begin{array}{c}\mathrm{A}_{4} \\
\text { (Bölge 4) }\end{array}$} & $\mathrm{KV}_{1}$ & i & oi & $\mathrm{i}$ & çi & oi & oi & 0 & çì & oi & Çì & i & i & 0 & oi \\
\hline & $\mathrm{KV}_{2}$ & $i$ & oi & çi & çi & 0 & oi & i & Çأ & oi & Çأ & i & i & 0 & oi \\
\hline & $\mathrm{KV}_{3}$ & $i$ & oi & i & çi & 0 & i & oi & çi & $i$ & Çi & $i$ & çi & oi & oi \\
\hline & $\mathrm{KV}_{4}$ & i & oi & çi & çi & $\mathrm{K}$ & oi & i & çi & oi & Çí & $i$ & çi & 0 & oi \\
\hline \multirow{4}{*}{$\begin{array}{c}A_{5} \\
\text { (Bölge 5) }\end{array}$} & $\mathrm{KV}_{1}$ & çi & i & çi & çi & 0 & oi & 0 & Çì & $i$ & çi & i & çi & oi & oi \\
\hline & $\mathrm{KV}_{2}$ & i & oi & çi & çi & Oi & $i$ & $i$ & Çì & $i$ & Çi & $i$ & i & 0 & $i$ \\
\hline & $\mathrm{KV}_{3}$ & i & i & Çi & çi & 0 & i & i & çi & $i$ & Çi & $i$ & Çi & oi & oi \\
\hline & $\mathrm{KV}_{4}$ & i & oi & çi & çi & oi & oi & $i$ & Çأ & oi & Çأ & Çأ & Çأ & $i$ & oi \\
\hline
\end{tabular}

Ek 3: Kriterlerin Bulanık Ağırlık Matrisi

\begin{tabular}{|c|c|c|c|c|c|c|c|c|c|c|c|c|}
\hline & \multicolumn{3}{|c|}{$C_{1}$} & \multicolumn{3}{|c|}{$C_{2}$} & \multicolumn{3}{|c|}{$C_{3}$} & \multicolumn{3}{|c|}{$C_{4}$} \\
\hline & 1 & $\mathrm{~m}$ & u & 1 & $\mathrm{~m}$ & u & 1 & $\mathrm{~m}$ & u & 1 & $\mathrm{~m}$ & u \\
\hline KV1 & 0,5 & 0,7 & 0,9 & 0,5 & 0,7 & 0,9 & 0,7 & 0,9 & 1 & 0,7 & 0,9 & 1 \\
\hline KV2 & 0,3 & 0,5 & 0,7 & 0,3 & 0,5 & 0,7 & 0,5 & 0,7 & 0,9 & 0,7 & 0,9 & 1 \\
\hline KV3 & 0,3 & 0,5 & 0,7 & 0,5 & 0,7 & 0,9 & 0,3 & 0,5 & 0,7 & 0,5 & 0,7 & 0,9 \\
\hline KV4 & 0,5 & 0,7 & 0,9 & 0,3 & 0,5 & 0,7 & 0,7 & 0,9 & 1 & 0,7 & 0,9 & 1 \\
\hline \multirow[t]{3}{*}{ Ortalama } & 0,40 & 0,60 & 0,80 & 0,40 & 0,60 & 0,80 & 0,55 & 0,75 & 0,90 & 0,65 & 0,85 & 0,98 \\
\hline & \multicolumn{3}{|c|}{$C_{5}$} & \multicolumn{3}{|c|}{$C_{6}$} & \multicolumn{3}{|c|}{$C_{7}$} & \multicolumn{3}{|c|}{$\mathrm{C}_{8}$} \\
\hline & I & $\mathrm{m}$ & u & 1 & $\mathrm{~m}$ & u & 1 & $\mathrm{~m}$ & u & 1 & $\mathrm{~m}$ & u \\
\hline KV1 & 0,9 & 1 & 1 & 0,9 & 1 & 1 & 0,5 & 0,7 & 0,9 & 0,5 & 0,7 & 0,9 \\
\hline KV2 & 0,7 & 0,9 & 1 & 0,7 & 0,9 & 1 & 0,3 & 0,5 & 0,7 & 0,3 & 0,5 & 0,7 \\
\hline KV3 & 0,9 & 1 & 1 & 0,7 & 0,9 & 1 & 0,5 & 0,7 & 0,9 & 0,3 & 0,5 & 0,7 \\
\hline KV4 & 0,7 & 0,9 & 1 & 0,7 & 0,9 & 1 & 0,3 & 0,5 & 0,7 & 0,3 & 0,5 & 0,7 \\
\hline Ortalama & 0,80 & 0,95 & 1 & 0,75 & 0,93 & 1 & 0,40 & 0,60 & 0,80 & 0,35 & 0,55 & 0,75 \\
\hline
\end{tabular}


Ek 4: Bulanık Karar Matrisi

\begin{tabular}{|c|c|c|c|c|c|c|c|}
\hline \multirow{2}{*}{ Alternatifler } & \multirow{2}{*}{ Karar Vericiler } & \multicolumn{3}{|c|}{$C_{1}$} & \multicolumn{3}{|c|}{$C_{2}$} \\
\hline & & I & $\mathrm{m}$ & u & 1 & $\mathrm{~m}$ & u \\
\hline \multirow{4}{*}{$\begin{array}{c}\text { A1 } \\
\text { (Bölge 1) }\end{array}$} & KV1 & 7 & 9 & 10 & 3 & 5 & 7 \\
\hline & KV2 & 3 & 5 & 7 & 5 & 7 & 9 \\
\hline & KV3 & 7 & 9 & 10 & 3 & 5 & 7 \\
\hline & KV4 & 7 & 9 & 10 & 5 & 7 & 9 \\
\hline & Ortalama & 6,00 & 8,00 & 9,25 & 4,00 & 6,00 & 8,00 \\
\hline \multirow{4}{*}{$\begin{array}{c}\text { A2 } \\
\text { (Bölge 2) }\end{array}$} & KV1 & 9 & 10 & 10 & 7 & 9 & 10 \\
\hline & KV2 & 7 & 9 & 10 & 5 & 7 & 9 \\
\hline & KV3 & 9 & 10 & 10 & 7 & 9 & 10 \\
\hline & KV4 & 7 & 9 & 10 & 9 & 10 & 10 \\
\hline & Ortalama & 8,00 & 9,50 & 10,00 & 7,00 & 8,75 & 9,75 \\
\hline \multirow{4}{*}{$\begin{array}{c}\text { A3 } \\
\text { (Bölge 3) }\end{array}$} & KV1 & 7 & 9 & 10 & 3 & 5 & 7 \\
\hline & KV2 & 3 & 5 & 7 & 3 & 5 & 7 \\
\hline & KV3 & 3 & 5 & 7 & 3 & 5 & 7 \\
\hline & KV4 & 7 & 9 & 10 & 5 & 7 & 9 \\
\hline & Ortalama & 5,00 & 7,00 & 8,50 & 3,50 & 5,50 & 7,50 \\
\hline \multirow{4}{*}{$\begin{array}{c}\text { A4 } \\
\text { (Bölge 4) }\end{array}$} & KV1 & 7 & 9 & 10 & 5 & 7 & 9 \\
\hline & KV2 & 7 & 9 & 10 & 5 & 7 & 9 \\
\hline & KV3 & 7 & 9 & 10 & 5 & 7 & 9 \\
\hline & KV4 & 7 & 9 & 10 & 5 & 7 & 9 \\
\hline & Ortalama & 7,00 & 9,00 & 10,00 & 5,00 & 7,00 & 9,00 \\
\hline \multirow{5}{*}{$\begin{array}{c}\text { A5 } \\
\text { (Bölge 5) }\end{array}$} & KV1 & 9 & 10 & 10 & 7 & 9 & 10 \\
\hline & KV2 & 7 & 9 & 10 & 5 & 7 & 9 \\
\hline & KV3 & 7 & 9 & 10 & 7 & 9 & 10 \\
\hline & KV4 & 7 & 9 & 10 & 5 & 7 & 9 \\
\hline & Ortalama & 7,50 & 9,25 & 10,00 & 6,00 & 8,00 & 9,50 \\
\hline
\end{tabular}


